\title{
INFLUENCE OF FREEZE-THAW ACTION ON DEFORMATION-STRENGTH CHARACTERISTICS AND PARTICLE CRUSHABILITY OF VOLCANIC COARSE-GRAINED SOILS
}

\author{
TAtSuya IshiKawa ${ }^{\text {i) }}$ and Seirchi MiURA ${ }^{\text {ii) }}$
}

\begin{abstract}
The objective of this study is to evaluate the effect of freeze-thaw action on the deformation-strength characteristics of crushable volcanic coarse-grained soils, wherein significant particle breakage occurs even under relatively low stress levels and saturated conditions. A series of monotonic triaxial compression tests was performed for volcanic coarsegrained soils under various freeze-thaw histories. On the basis of the test results, we examined the above-mentioned effect and the relationship between the degree of particle breakage and the freeze-thaw history. The results indicate that the degree of particle breakage under consolidation and shear increased with freeze-thaw action; and consequently, the strength and the stiffness of the soils decreased with an increase in the number of freeze-thaw cycles. Moreover, to examine the influence of freeze-thaw action on the single-particle hardness of volcanic coarse-grained soils, single-particle crushing tests were conducted. The test results revealed that volcanic soil particles become more fragile after being exposed to freeze-thaw action, and as a result, the degree of particle breakage increases. These results indicate that the freeze-thaw action has a strong influence on the deformation-strength characteristics of crushable volcanic soils in terms of an increase in particle breakage, even if the soils lack frost-heave characteristics.
\end{abstract}

Key words: freeze-thaw testing, particle breakage, shear strength, triaxial test, volcanic coarse-grained soil (IGC: D3/D6/D8)

\section{INTRODUCTION}

Much of Japan is covered by volcanic soils, which have been produced since the quaternary period due to volcanic activity. Even in Hokkaido, a cold and snowy island in northern Japan, volcanic soils are widely distributed over $40 \%$ of the total area. Volcanic soils are known to show different behavior from that of clay or sand, and have been the subject of much research, as they have caused complicated geotechnical engineering problems (Miura and Yagi, 2003). Volcanic soil deposits possess diverse inherent properties that depend on the various modes of deposition and the conditions of the depositional environment, which are mostly dominated by the local geology, the local topography, and the local climatic conditions. From a geotechnical engineering point of view, the most distinctive feature of the volcanic coarse-grained soils in Hokkaido is the tendency for particle breakage, which leads to a degradation in static and dynamic deformation-strength characteristics (Miura et al., 1996a, b; Yagi and Miura, 2004). Crushing of the particles of Hokkaido's volcanic coarse-grained soils can be observed even under relatively low stress levels, i.e., the subsurface layer subjected to freeze-thaw action with snowfall.
Therefore, cyclic freeze-thaw action may seriously influence the rate of particle breakage.

As a matter of fact, the slope failure that occurs at the subsurface layer during the snow-melting season in Hokkaido is intense. This subsurface failure is deemed to be caused by an increase in the degree of saturation arising from the melting of snow and/or the degradation in the physical properties and the mechanical characteristics of the soils caused by freeze-thaw action. For example, the growth of ice lenses within frost-susceptible soils and their subsequent hollowing with thawing may weaken the structure of the soil skeleton, owing to the formation of local cracks and a reduction in soil density (Qi et al., 2006). Likewise, for volcanic coarse-grained soils, which have multifarious physical properties and display complex mechanical behavior, the particle breakage caused by the freezing of pore water may result in a degradation of the physical properties and the mechanical characteristics. Accordingly, it is imperative to establish a precise predictive method for slope failure in Hokkaido to examine the influence of freeze-thaw action on the deformation-strength characteristics of soils, irrespective of their frost susceptibility, and to identify endogenous and exogenous factors affecting slope failure in the snow-

i) Associate Professor, Faculty of Engineering, Hokkaido University, Japan (t-ishika@eng.hokudai.ac.jp).

ii) Professor, ditto.

The manuscript for this paper was received for review on November 18, 2010; approved on April 14, 2011.

Written discussions on this paper should be submitted before May 1, 2012 to the Japanese Geotechnical Society, 4-38-2, Sengoku, Bunkyo-ku, Tokyo 112-0011, Japan. Upon request the closing date may be extended one month. 
melting season.

A large number of experimental studies have been conducted on the mechanical behavior of frost-susceptible geomaterials, such as clay and silt. For example, Aoyama et al. (1979) showed that in an overconsolidated cohesive soil with a high silt content, freeze-thaw action under undrained conditions causes the cohesion to decrease, but the internal friction angle does not change. Aoyama et al. (1977) also demonstrated a striking reduction in the unconfined compressive strength due to freeze-thaw sequences depending on the water content of the specimen and the number of freeze-thaw cycles. The reduction was shown to be due to factors such as lower density and the development of microcracks inside the specimen. Ono and Wada (2003) reported a series of undrained triaxial tests on saturated cohesive soils exposed to freeze-thaw sequences. For normally consolidated clay, the strength increased, showing a behavior similar to that of overconsolidated clay. For clay with a high overconsolidation ratio, the degree of overconsolidation decreased. This indicates that the effect of freeze-thaw action on the shear behavior of clay depends on its overconsolidation ratio. On the other hand, studies on freeze-thaw in non-frostsusceptible geomaterials, such as cohensionless soils, have mainly been conducted for the purpose of increasing the reliability of freezing sampling. Goto (1993) revealed that when a non-frost-susceptible geomaterial is frozen under drained conditions and beyond a certain confining pressure, the liquefaction strength and shear modulus of the thawed samples under a small strain are approximately the same as those prior to freezing. It can be seen from these studies that the effect of the freeze-thaw action is a popular area of research, resulting in various findings. However, little attention has been paid to non-frostsusceptible crushable geomaterials, such as the volcanic coarse-grained soils spread across Hokkaido.

Ishikawa et al. (2008) developed a new triaxial apparatus that can simulate freeze-thaw sequences similar to those experienced by in situ soils in cold regions before triaxial compression tests, and reported the influence of the freeze-thaw action on the mechanical behavior of volcanic coarse-grained soils, wherein significant particle crushing takes place during the loading and deformation processes.

The objective of this study is to reveal the effect of cyclic freeze-thaw action on the deformation-strength characteristics of crushable volcanic coarse-grained soils under saturated conditions from the viewpoint of particle crushability. This is done to examine the mechanical behavior of fragmental volcanic soil grounds in the snowmelting season. Following this, in addition to the authors' preceding study, a series of monotonic triaxial compression tests on volcanic coarse-grained soils, which were a type of non-frost susceptible geomaterial, were performed under various freeze-thaw histories with the freeze-thaw triaxial apparatus. The test results were used to examine the change in deformation-strength characteristics due to freeze-thaw action and the effect of the freeze-thaw sequences on particle crushability. To exa- mine the influence of freeze-thaw action on the singleparticle hardness of such soils, single-particle crushing tests were also performed.

\section{METHODOLOGY}

\section{Freeze-thaw Triaxial Apparatus}

A schematic diagram and a photo of the freeze-thaw triaxial apparatus are shown in Figs. 1(a) and (b), respectively. The apparatus has a cooling system that allows the temperature of the cap and the pedestal to be controlled independently. The difference in temperature between the cap and the pedestal can be arbitrarily set, producing the desired temperature gradient in a triaxial specimen. In addition, water at a controlled temperature of $2{ }^{\circ} \mathrm{C}$ is circulated through an opening between the inner cell and the outer cell, as shown in Fig. 1(a), thus allowing the temperature inside the triaxial cell to be controlled and giving it a certain amount of insulation. Moreover, since the acrylic cylindrical cell for the frost-heave simulation, attached via a $0.3-\mathrm{mm}$-thick membrane to the outer surface of the specimen, allows for the lateral displacement to be constrained during freezing and thawing, one-dimensional frost heave can be replicated in the specimen. Accordingly, the apparatus can apply a freeze-thaw sequence to the triaxial specimen similar to that experienced by in situ soils in cold regions.

After the freeze-thaw process, monotonic loading triaxial compression tests can be performed for coarsegrained soils under drained and undrained conditions. Axial load is applied to the specimen by the strain control method with a direct drive motor (DDM). The measurements of stress and strain in the freeze-thaw triaxial compression tests were conducted as follows. The axial stress $\left(\sigma_{\mathrm{a}}\right)$ was measured with the load cell installed inside the triaxial cell, while the axial strain $\left(\varepsilon_{\mathrm{a}}\right)$ was measured with the external displacement transducer (dial gauge). The volumetric change $\left(\varepsilon_{\mathrm{v}}\right)$ in the specimen, equal to the volume of drainage during testing, was measured with a double tube burette connected to the pedestal. Platinum resistance thermometers were embedded in the cap and the pedestal to measure the temperature at the top and bottom ends of the specimen.
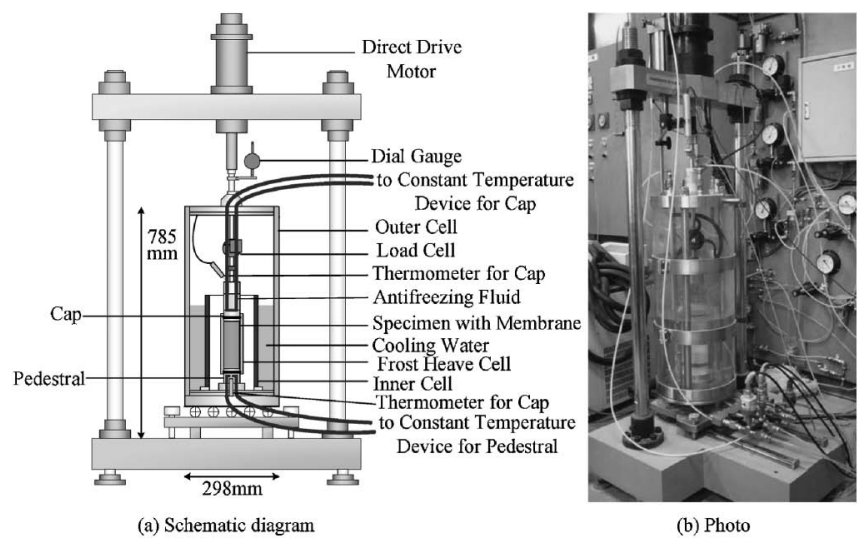

Fig. 1. Freeze-thaw triaxial apparatus 


\section{Soil Samples}

Three test materials were employed, namely, two different volcanic coarse-grained soils, Tomikawa volcanic soil and Touhoro volcanic soil, and Japanese standard sand (Toyoura sand). The volcanic coarse-grained soils were taken from natural deposits in Hokkaido, as shown in Fig. 2. Tomikawa volcanic soil belongs to the Shikotsu primary tephra deposited by the eruption of Shikotsu caldera approximately 31,000-34,000 years ago. Touhoro volcanic soil is a fallen pumice stone, which was volcanic debris from the eruption of Mashu caldera, estimated to have occurred 11,000-13,000 years ago. Both samples were extracted at depths of over $1.5 \mathrm{~m}$ below ground level (lower than the freezing depths during the twenty years from 1981 to 2000). However, sufficient information is

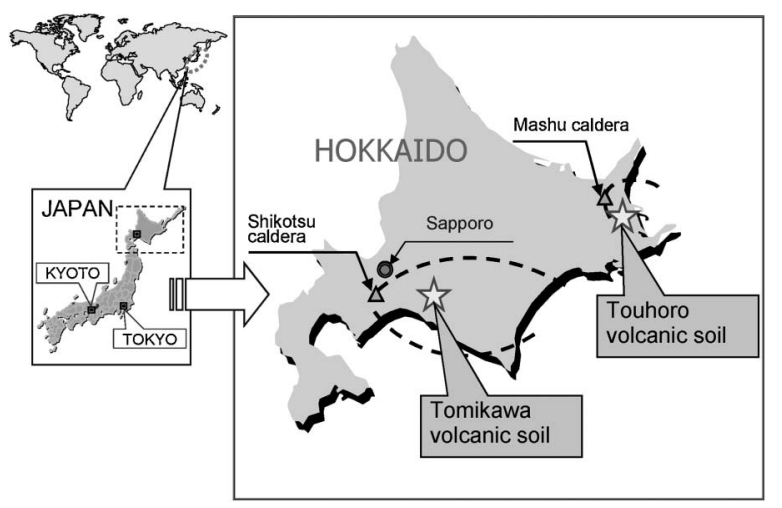

Fig. 2. Sampling sites of volcanic soils

Table 1. Physical properties of samples

\begin{tabular}{cccccc}
\hline Name of sample & $\begin{array}{c}\rho_{\mathrm{s}} \\
\left(\mathrm{g} / \mathrm{cm}^{3}\right)\end{array}$ & $\begin{array}{c}\rho_{\mathrm{dmax}} \\
\left(\mathrm{g} / \mathrm{cm}^{3}\right)\end{array}$ & $\begin{array}{c}\rho_{\mathrm{dmin}} \\
\left(\mathrm{g} / \mathrm{cm}^{3}\right)\end{array}$ & $\begin{array}{c}D_{50} \\
(\mathrm{~mm})\end{array}$ & $\begin{array}{c}F_{\mathrm{c}, \text { initial }} \\
(\%)\end{array}$ \\
\hline Tomikawa volcanic soil & 2.22 & 0.522 & 0.426 & 1.10 & 1.00 \\
\hline Touhoro volcanic soil & 2.44 & 0.680 & 0.483 & 5.00 & 1.97 \\
\hline Toyoura sand & 2.65 & 1.648 & 1.354 & 0.18 & 0.00 \\
\hline
\end{tabular}

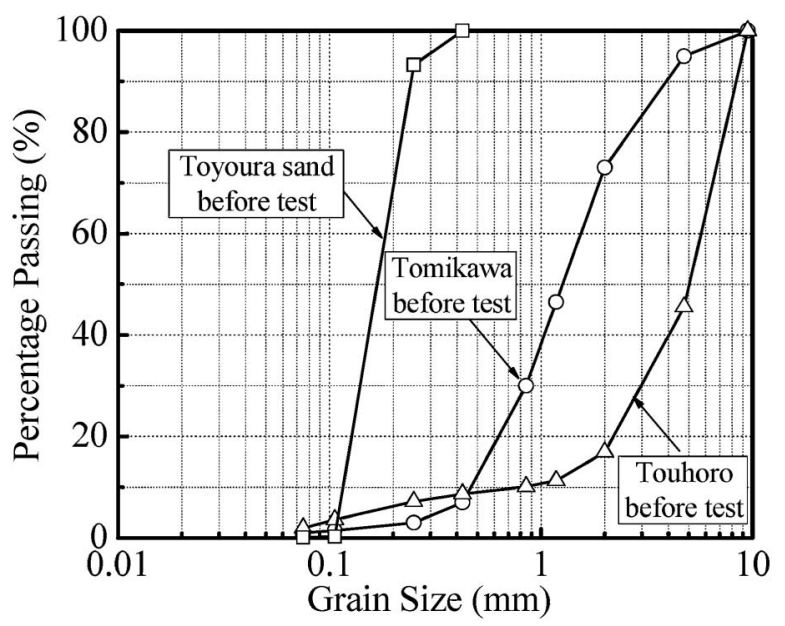

Fig. 3. Grain-size distribution curves of samples not available on the past freeze-thaw history of the samples. Accordingly, in this study, we examine the influence of future freeze-thaw history on the mechanical behavior of both volcanic soils.

The physical properties and the grain-size distribution curves of the two different volcanic soils are shown in Table 1 and Fig. 3, respectively, along with those of Toyoura sand for comparison. The maximum dry density, $\rho_{\mathrm{dmax}}$, and the minimum dry density, $\rho_{\mathrm{dmin}}$, were obtained according to the test method for minimum and maximum densities of sands (JIS A 1224), although the volcanic soil samples had maximum grain sizes beyond the appropriate range of JIS A 1224. Both volcanic soils have low maximum and minimum dry densities $\left(\rho_{\mathrm{dmax}}\right.$ and $\rho_{\text {dmin }}$ ), because their constituent particles are very porous due to the large number of intra-particle voids. As shown in Fig. 3, both volcanic soils characteristically contain coarse and fine fractions, and they are coarser than Toyoura sand, although their fines fraction contents $\left(F_{\mathrm{c}}\right)$ are low, at $1 \%-2 \%$. Touhoro volcanic soil in particular is extremely coarse and well-graded. Furthermore, from past studies (Miura and Yagi, 1997; Nakata et al., 1998), it has been revealed that both volcanic soils exhibit remarkable particle crushability even under relatively low stress levels. Particle breakage has been found by previous research to increase with the effective mean principal stress $\left(p^{\prime}\right)$ and the effective stress ratio $\left(\eta=q / p^{\prime}\right.$ and $q$ : deviator stress) (Miura and Yagi, 1997). Of these, Touhoro volcanic soil is known to display the most striking particle crushability (Nakata et al., 1998). For comparison with the volcanic coarse-grained soils, Toyoura sand, which does not undergo particle breakage within the stress levels used in this study, is employed.

\section{EXPERIMENTAL PROGRAMS}

In this study, two different types of laboratory element tests were conducted on the volcanic coarse-grained soils, namely, freeze-thaw triaxial compression tests and singleparticle crushing tests. The loading conditions for the freeze-thaw triaxial compression tests are shown in Fig. 4. Note that these tests were conducted in the following steps: a) Preparation of the test specimen, b) Freeze-thaw tests, c) Triaxial compression tests, and d) Particle size analysis. Details of the testing steps are given below.

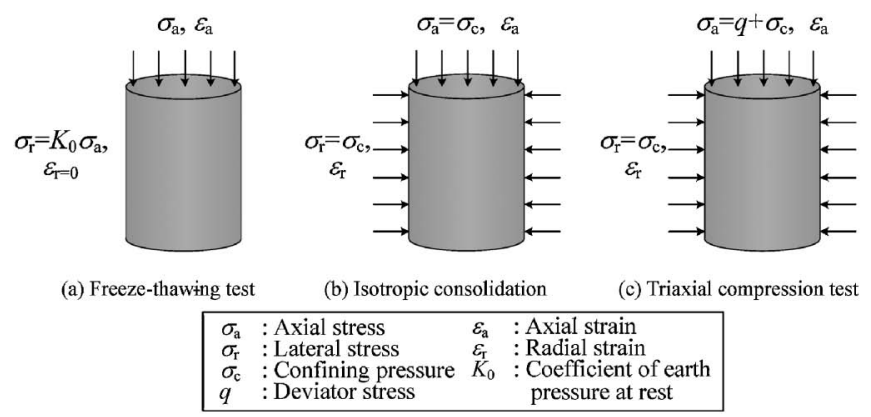

Fig. 4. Loading conditions in freeze-thaw triaxial compression tests 


\section{Preparation of Test Specimens}

A triaxial test specimen, initially $170 \mathrm{~mm}$ in height $(H)$ and $70 \mathrm{~mm}$ in diameter $(D)$, was prepared as follows. The volcanic soils obtained from the sampling sites were oven-dried at $110^{\circ} \mathrm{C}$ for 24 hours and then allowed to cool at a room temperature of about $20^{\circ} \mathrm{C}$. A cylindrical specimen was manufactured using the air pluviation method (Miura and Toki, 1982) by varying the falling height of the oven-dried volcanic soil samples. Here, to ensure the experimental accuracy of the ratio of maximum particle size to specimen diameter, the volcanic soil samples used in this study were restricted to materials that could be passed through a $9.5-\mathrm{mm}$ sieve. The initial dry densities of the specimens $\left(\rho_{\mathrm{d} 0}\right)$ were adjusted so that the dry density after consolidation $\left(\rho_{\mathrm{dc}}\right)$ would be equal to the in situ dry density ( $\left.\rho_{\text {din-situ }}\right)$ and that the initial density $\left(\rho_{\mathrm{d} 0}\right)$ of the specimen would become constant. Allowable variations in $\rho_{\mathrm{d} 0}$ and $\rho_{\mathrm{dc}}$ were limited to within $\pm 5 \%$ of the prescribed density. As for Toyoura sand, a cylindrical specimen was also prepared using the air-pluviation method with an air-dried sample, so that the initial relative density of the specimen $\left(D_{\mathrm{r}}\right)$ would be equal to $82 \%$ with reference to the experimental conditions in our previous researches.

Lubrication layers were not adopted at the interfaces between the specimen and the end platens (porus metals). Goto and Tatsuoka (1988) showed that the increase in the height to diameter ratio $(H / D)$ of the triaxial specimen reduces the effect of the friction between the specimen and the cap and the pedestal on the internal friction angle even in the absence of lubrication layers. Accordingly, the height to diameter ratio $(H / D)$ in this study was set to be equal to 2.4 with reference to the recommended range $(H / D=1.5$ to 2.5$)$ when preparing the soil specimens for the triaxial tests (JGS, 0520).

\section{Freeze-thaw Tests}

The freeze-thaw tests were conducted as follows. A triaxial specimen covered with a cell made of acrylic for frost heave was permeated from the bottom end of the specimen by de-aired water for around 3 hours until the degree of saturation reached approximately $80 \%$ or more. The specimen was then one-dimensionally consolidated by loading a weight corresponding to $\sigma_{\mathrm{a}}=12.2 \mathrm{kPa}$ via a loading rod on the top of the specimen to simulate the overburden pressure from the surface soil and also in consideration of the standard applied stress in the test method for the frost susceptibility of soils (JGS, 0172). Subsequently, the specimen was frozen by applying a thermal shock via the upper part of the cooling system and then thawed via the lower part, while allowing for water supply and drainage. Here, the difference in temperature between the upper and the lower ends of the specimen was fixed at $17^{\circ} \mathrm{C}$ (a temperature gradient through the specimen of $0.1^{\circ} \mathrm{C} / \mathrm{mm}$ ), and the cooling rate was fixed at $1.6^{\circ} \mathrm{C} / \mathrm{h}$. Then, the freezing and thawing rate $(U)$ for the freeze-thaw tests was usually set to be equal to $16.0 \mathrm{~mm} / \mathrm{h}$. In this study, the above-mentioned series of operations was defined as one freeze-thaw proc- ess cycle.

\section{Triaxial Compression Tests}

Monotonic triaxial compression tests were conducted as follows. Following the freeze-thaw tests, the frostheave cell was removed from the specimen. A saturated specimen was created by suctioning pore air from the dry specimens with high negative pressure, that is to say "the double vacuuming method (Ampadu and Tatsuoka, 1993)', and subsequently, permeating de-aired water into the voids. A back pressure of $200 \mathrm{kPa}$ was then applied to ensure the saturation of all the specimens and achieve a pore water pressure coefficient B-value of 0.96 or more. Next, the specimens were isotropically consolidated under the specified effective confining pressure $\left(\sigma_{\mathrm{c}}^{\prime}\right)$ of $49.0 \mathrm{kPa}$, or $98.0 \mathrm{kPa}$, until there was no further change in the axial displacement or the drainage volume. Subsequently, a deviator stress $(q)$ was continuously applied to the specimens under both fully drained (CD tests) and fully undrained ( $\overline{\mathrm{CU}}$ tests) conditions at a prescribed constant axial strain rate, while keeping $\sigma_{\mathrm{c}}^{\prime}$ constant. In consideration of the difference in permeability, the axial strain rate of the volcanic coarse-grained soils and the Toyoura sand was set to be equal to $0.2 \% / \mathrm{min}$ and $0.5 \%$ /min, respectively. Axial loading was completed after reaching an axial strain $\left(\varepsilon_{\mathrm{a}}\right)$ of about $30 \%$. During the loading process, the axial compressive force, axial deformation, and pore water pressure values in the $\overline{\mathrm{CU}}$ tests were recorded continuously and stored automatically by a computer program. In addition, for comparison, ordinary triaxial compression tests were performed under the same experimental conditions, except for the absence of the freeze-thaw process.

\section{Particle Size Analysis}

After testing, the particle size distribution of each test specimen was examined by a sieve analysis to assess the degree of particle breakage that a specimen underwent during the test. The sieve analysis was performed with due care so as not to induce any new particle breakage. The increment in fines content $\left(\Delta F_{\mathrm{c}}\right)$, which is the change in the fines content $\left(F_{\mathrm{c}}\right)$ of the tested specimens from that of the original specimens given in Eq. (1) (Nakata et al., 1998), was used to evaluate the degree of particle breakage. The fines content $\left(F_{\mathrm{c}}\right)$ is simply the percent of particles finer than a grain size $0.075 \mathrm{~mm}$ in diameter, as shown in the particle size distribution curve in Fig. 5.

$$
\Delta F_{\mathrm{c}}=F_{\mathrm{c}}^{\prime}-F_{\mathrm{c}}
$$

Here, $F_{\mathrm{c}}$ and $F_{\mathrm{c}}^{\prime}$ are the fines contents before and after testing. The validity of $\Delta F_{\mathrm{c}}$ as an evaluation index has been discussed in a previous research (Miura and Yagi, 1997).

\section{Triaxial Compression Tests for Freeze-reconstituted Specimens}

Since freeze-thaw triaxial compression tests require much time and effort, triaxial compression tests for freeze-reconstituted specimens were performed separately to develop a simple testing method using the freeze- 


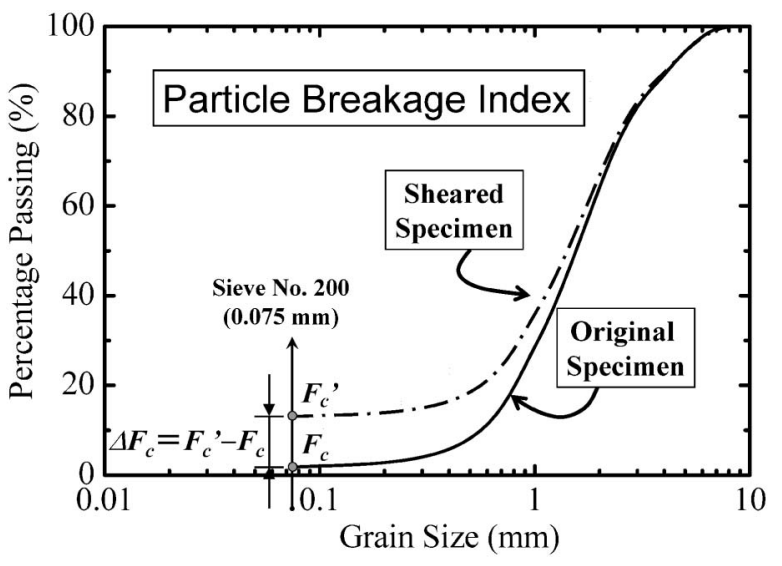

Fig. 5. Definition of particle breakage index, $\Delta F_{\mathrm{c}}$

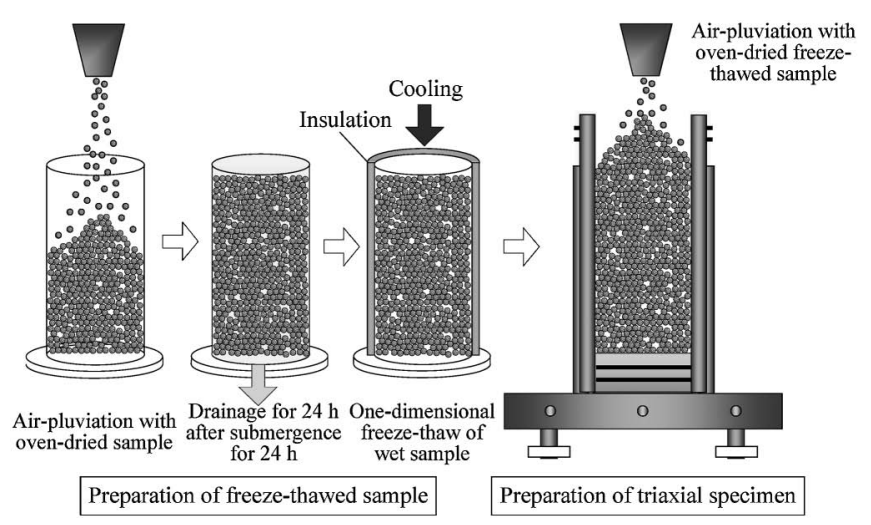

Fig. 6. Preparation of freeze-reconstituted specimen

thawed samples. The method is described as follows (Fig. 6). Firstly, the freeze-thawed sample was prepared by soaking it for 24 hours, then draining it by gravity for 24 hours (this paper calls this state the "saturated surfacedry condition"), freezing it in a freezer for 24 hours, and finally thawing it at room temperature for 24 hours. In this study, this series of operations is also defined as one freeze-thaw process cycle. Next, a freeze-reconstituted specimen was prepared by the air-pluviation method in the same way as for freeze-thaw triaxial compression tests. Subsequently, the above-mentioned triaxial compression tests and a particle size analysis were performed.

\section{Single-particle Crushing Tests}

Single-particle crushing tests (Miura et al., 1999) for the freeze-thawed volcanic coarse-grained soils were conducted as follows to evaluate the effect of the freeze-thaw sequences on the hardness of the individual particles. Freeze-thawed samples were prepared using the same method as the above-mentioned triaxial compression tests for freeze-reconstituted specimen. As a sample of the single-particle crushing test, 500 particles extracted at random from the freeze-thawed sample were oven-dried at $110^{\circ} \mathrm{C}$ for 24 hours and then allowed to cool at room temperature. Next, a freeze-thawed soil particle was gently pinched between loading rods in the direction of the

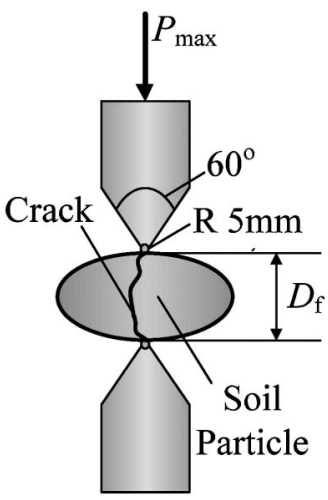

Fig. 7. Single-particle crushing test

minor axis of the elliptical particle, as shown in Fig. 7, and after measuring the initial height of the particle, an axial load $(P)$ was applied to it continuously in the displacement-controlled manner with a constant axial displacement rate of $0.3 \mathrm{~mm} / \mathrm{min}$. Here, both the top and bottom rods were cone-shaped point-loading rods with a radius of curvature $R=5 \mathrm{~mm}$ and ends at a scissor-angle of $60^{\circ}$, making this test a point-loading split test. Accordingly, the strength of single-particle crushing $\left(S_{\mathrm{t}}\right)$ in this study is given in the form of the crushing strength at point loads, calculated from the equation proposed by Hiramatsu et al. (1965):

$$
S_{\mathrm{t}}=0.9 \cdot P_{\max } / D_{\mathrm{f}}^{2}
$$

Here, $P_{\max }$ is the maximum axial load and $D_{\mathrm{f}}$ is the particle height at failure.

\section{RESULTS AND DISCUSSION}

\section{Behavior of Soil Specimens during the Freeze-thaw Process}

We first discuss the frost-heave behavior of the crushable volcanic coarse-grained soils and the non-crushable sand. Figure 8 plots the temperatures of the cap $\left(T_{\mathrm{w}}\right)$ and the pedestal $\left(T_{\mathrm{c}}\right)$, the volume of drainage $(\Delta V)$, and the axial displacement of the cap $(\Delta H)$ against the elapsed time $(t)$ in the freeze-thaw tests under a constant freezing and thawing rate $(U)$ of $16.0 \mathrm{~mm} / \mathrm{h}$ on the two volcanic soils and the Toyoura sand. Similarly, Figure 9 shows the relationships for the Touhoro volcanic soil obtained from freeze-thaw tests under different freezing and thawing rates. Note that $t$ is defined as the elapsed time after the thermal shock, and the number of freeze-thaw process cycles $\left(N_{\mathrm{f}}\right)$ in Fig. 8 is five. The axial displacement and the volume of drainage in these figures were initialized to zero after loading the specimen with an overburden pressure of $12.2 \mathrm{kPa}$. Pore water drains out of the soil specimens as the temperature decreases and water is soaked up by the specimens as the temperature increases after the temperature drop; the axial displacement of the specimens is unchanged with temperature during freezing. These results indicate that a decrease in temperature causes the in situ freezing of pore water, a phenomenon that was 

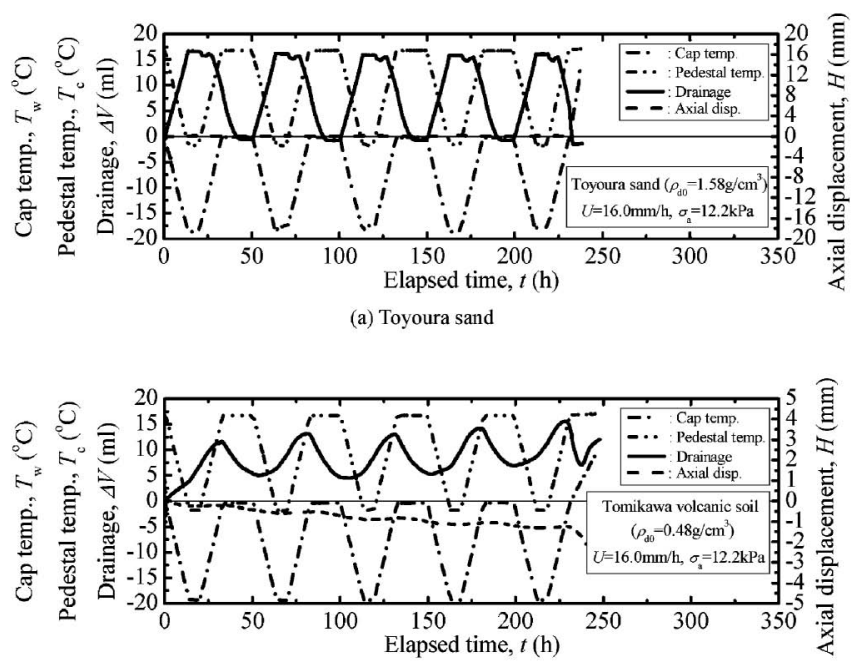

(b) Tomikawa volcanic soil

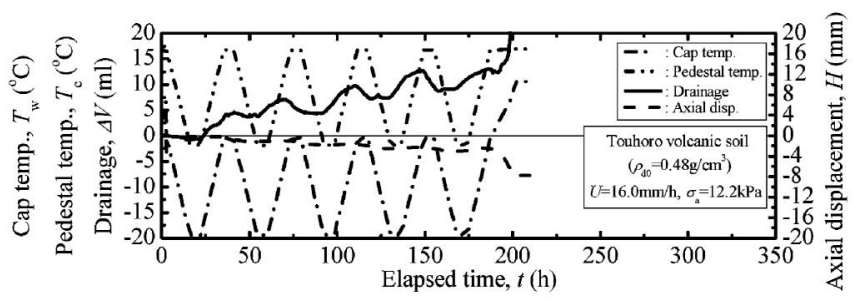

(c) Touhoro volcanic soil

Fig. 8. Frost-heave behavior during freeze-thaw tests

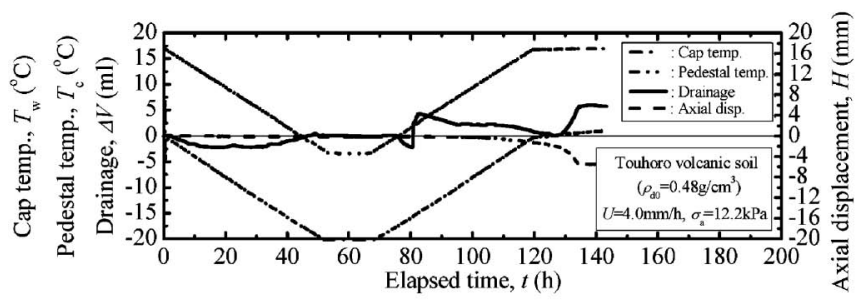

(a) Freezing rate $U=4.0 \mathrm{~mm} / \mathrm{h}$
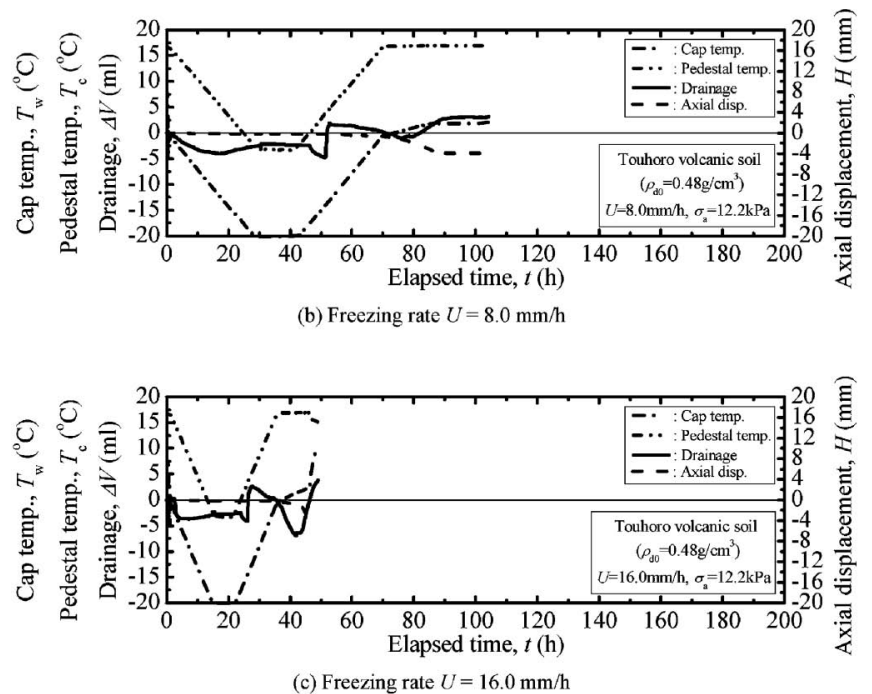

Fig. 9. Influence of freezing rate on frost-heave behavior (Touhoro volcanic soil)

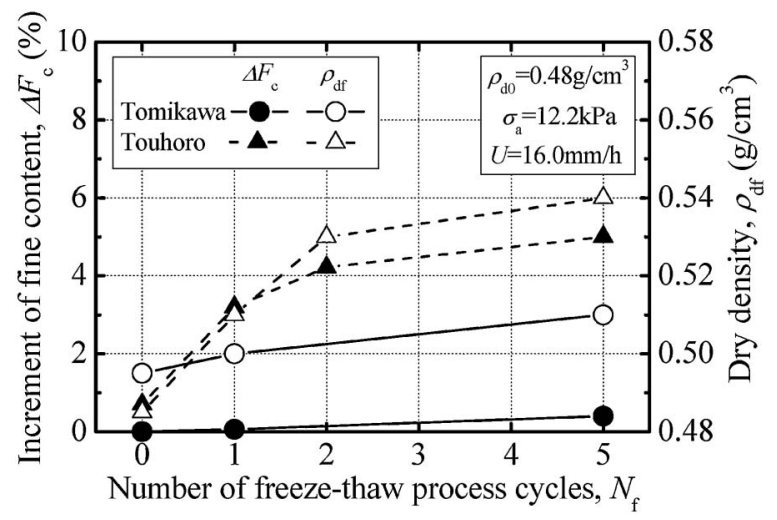

Fig. 10. Influence of freeze-thaw history on physical properties

displayed in all samples used in this study. Frost heave could barely be observed. Furthermore, the heights of the specimens before and after the freeze-thaw process were almost equal to those for Toyoura sand, while both volcanic coarse-grained soils exhibited a large subsidence and an increased density after thawing with an increasing $N_{\mathrm{f}}$. The increase in density of the volcanic soils caused by the freeze-thaw settlement also differs from the reduction in density due to the development of microcracks followed by the melting of ice lenses within frost-susceptible geomaterials in the above-mentioned past research works (e.g., Aoyama et al., 1977). The reason why the deformation during the freeze-thaw process and the change in density before and after the freeze-thaw process varies with the soil sample seems to be due to the difference in particle crushability and frost susceptibility. On the other hand, the freezing and thawing rate has little influence on the above-mentioned behavior of the soil specimens during freeze-thaw, as shown in Fig. 9, although the freezing and thawing rate in this study is higher than the recommended value in the test method for the frost susceptibility of soils (JGS, 0172).

Next, we discuss the effect of the freeze-thaw history on the physical properties of the two volcanic soil samples. Figure 10 shows the relationships of the densities after the freeze-thaw $\left(\rho_{\mathrm{df}}\right)$, as well as the increment in fines content $\left(\Delta F_{\mathrm{c}}\right)$, to the number of freeze-thaw process cycles $\left(N_{\mathrm{f}}\right)$ for both volcanic soils with the constant initial dry density $\left(\rho_{\mathrm{d} 0}\right)$. Note that points where $N_{\mathrm{f}}=0$ show the results before any freeze-thaw sequences and the $\Delta F_{\mathrm{c}}$ at $N_{\mathrm{f}}=0$ shows particle breakage under an overburden pressure of $12.2 \mathrm{kPa}$. Both $\rho_{\mathrm{df}}$ and $\Delta F_{\mathrm{c}}$ increase with an increasing $N_{\mathrm{f}}$, although the rates of increase gradually decrease with an increasing $N_{\mathrm{f}}$ for the second and subsequent times. The tendency for particle breakage from the freeze-thaw action is predominant in the Touhoro volcanic soil, which exhibits higher particle crushability than the Tomikawa volcanic soil. These results indicate that a significant degree of particle breakage is caused by the cyclic freeze-thaw actions in crushable volcanic coarsegrained soils, and that particle breakage brings about the volumetric contraction of the soil specimens because the particle skeleton structure is transformed into a denser 


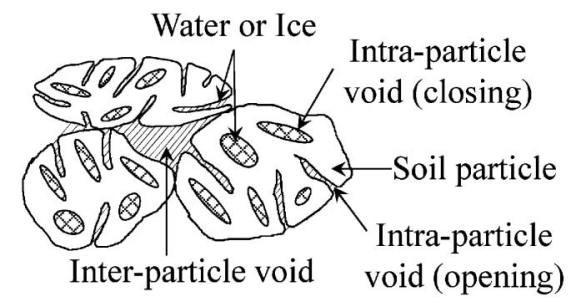

Fig. 11. Void structure for volcanic coarse-grained soil (Revision of Nakata and Miura, 2007)

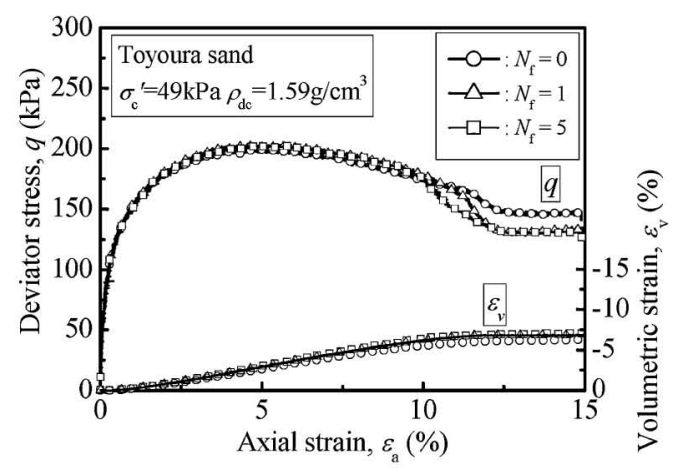

(a) Toyoura sand

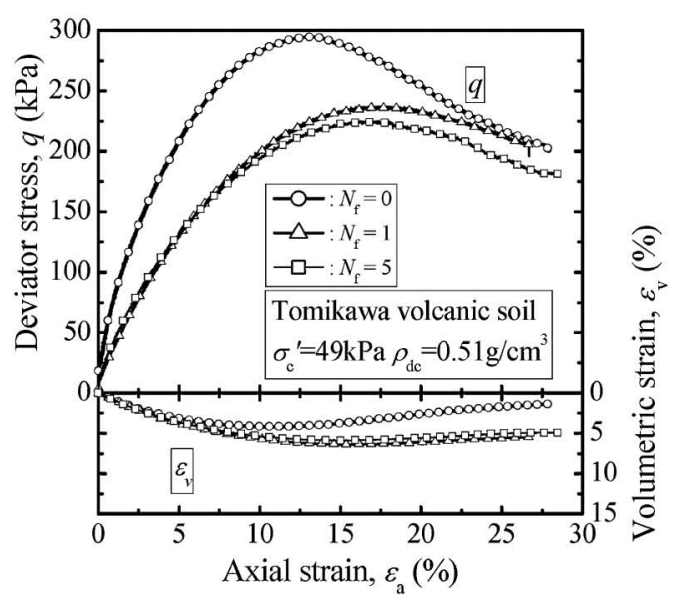

(b) Tomikawa volcanic soil

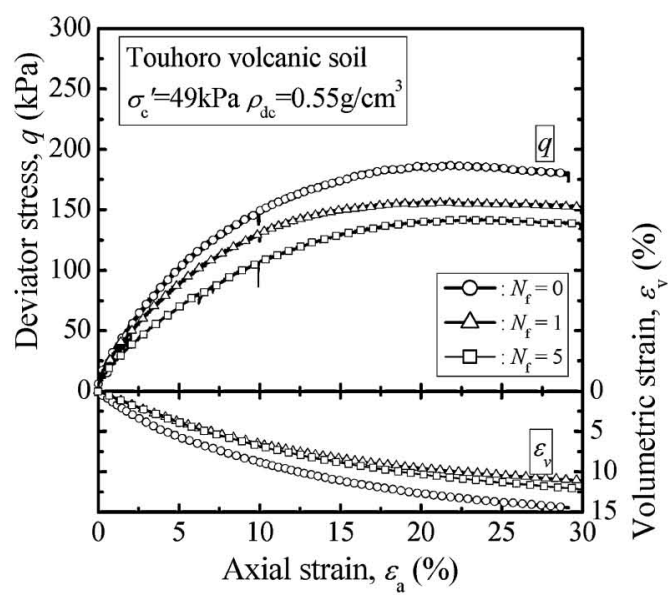

(c) Touhoro volcanic soil

Fig. 12. Comparison of stress-strain-dilatancy relationships between volcanic soils and sand $\left(\rho_{\mathrm{dc}}=\right.$ const. $)$ structure than before. Particle breakage induced by the freeze-thaw action in volcanic coarse-grained soils seems to be because some cracks in the very porous constituent particles expand as the pore water freezes inside the intraparticle voids, as shown in Fig. 11 (Nakata and Miura, 2007), and consequently, the particle becomes more fragile. This subject will be discussed further in the following section.

\section{Effect of Freeze-thaw Action on Shearing Behavior of Volcanic Coarse-grained Soils}

We will now discuss the effect of the freeze-thaw history on the stress-strain-dilatancy relationship of crushable volcanic coarse-grained soils. Figure 12 shows the typical relationships between freeze-thawed specimens and nonfreeze-thawed specimens for deviator stress $(q)$, volumetric strain $\left(\varepsilon_{\mathrm{v}}\right)$, and axial strain $\left(\varepsilon_{\mathrm{a}}\right)$ in CD tests on the two volcanic soils and the Toyoura sand, with the specified initial dry density adjusted to maintain a constant dry density after consolidation $\left(\rho_{\mathrm{dc}}\right)$. It should be noted that the difference between the results of the freeze-thawed and the non-freeze-thawed specimens can hardly be discerned

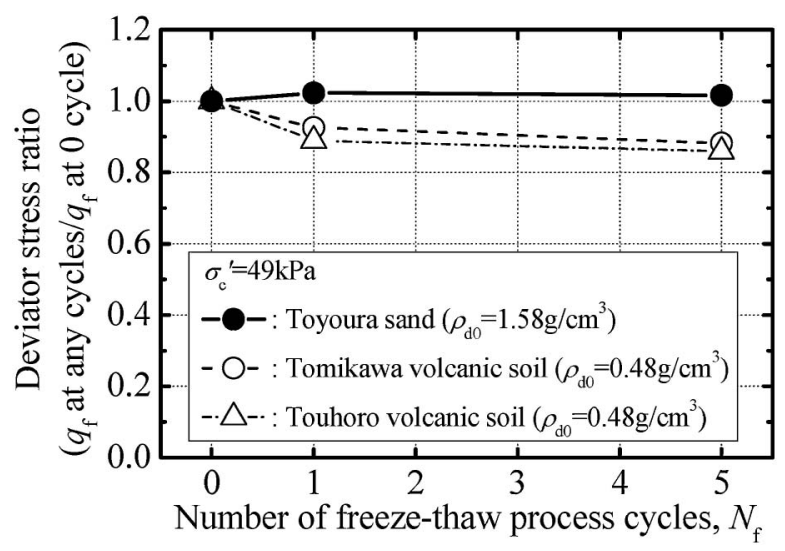

Fig. 13. Influence of freeze-thaw history on peak strength for specimens with the same $\rho_{\mathrm{d} 0}$

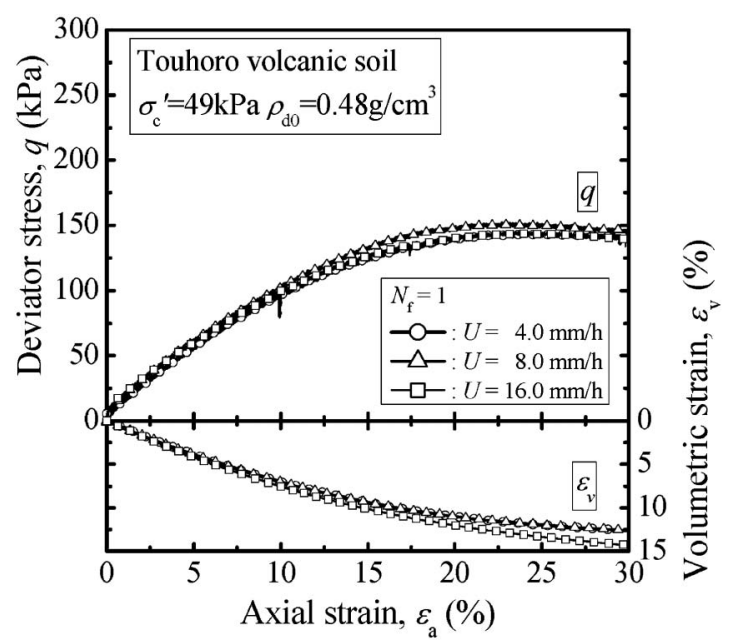

Fig. 14. Influence of freezing and thawing rate on stress-straindilatancy relationship $\left(\rho_{\mathrm{d} 0}=\right.$ const. $)$ 
by the shape of the consolidation curves during isotropic consolidation except for the values. For both volcanic soils, with an increasing axial strain, the deviator stress $(q)$ sharply increases to the peak strength at an axial strain $\left(\varepsilon_{\mathrm{a}}\right)$ of about $15 \%$, and then it gradually decreases to the residual strength, similar to the case for the Toyoura sand, regardless of the freeze-thaw history. Since the Toyoura sand did not undergo density changes due to the freeze-thaw actions, the $\rho_{\mathrm{dc}}$ was also constant regardless of whether or not a freeze-thaw process was experienced, with no significant difference in the $q-\varepsilon_{\mathrm{a}}-\varepsilon_{\mathrm{v}}$ relationships between the freeze-thawed specimens and the non-freezethawed specimens. In contrast, for volcanic coarsegrained soils, despite the fact that the increase in density was caused by the freeze-thaw actions (Fig. 10), the peak strength of the freeze-thawed specimens was lower compared to that of the non-freeze-thawed specimens, as shown in Fig. 13. Moreover, when the density increased notably during the freeze-thaw process, similar to the case for Touhoro volcanic soil, a tendency for difficulty in the contraction of the freeze-thawed specimens is observed, whereas the Tomikawa volcanic soil shows a tendency toward reduced dilation. The difference in the dilatancy behavior between the two soils may be due to the amount of fines content generated by the freeze-thaw action. These tendencies toward stress-strain-dilatancy relationships can be observed regardless of the freezing and thawing rates, and almost no quantitative difference in the deformation-strength characteristics, such as the peak strength or the volumetric strain, can be detected (Fig. 14).

Next, we discuss the effect of the freeze-thaw history on the deformation-strength characteristics of both volcanic soil samples. Figure 15 shows the secant deformation modulus $\left(E_{\mathrm{sec}}\right)$ at the axial strain $\left(\varepsilon_{\mathrm{a}}\right)$ of $0.1 \%$ and the ratio of peak strength $\left(q_{\mathrm{f}}\right)$ to effective confining pressure $\left(\sigma_{\mathrm{c}}^{\prime}\right)$, which were obtained from the stress-strain curves in Fig. 12, against the number of freeze-thaw process cycles $\left(N_{\mathrm{f}}\right)$ for the two volcanic soils. For both volcanic soils, the secant deformation modulus $\left(E_{\mathrm{sec}}\right)$ and the peak strength $\left(q_{\mathrm{f}}\right)$ decrease irrespective of $\sigma_{\mathrm{c}}^{\prime}$ with an increasing $N_{\mathrm{f}}$; however, the reduction in $E_{\mathrm{sec}}$ and $q_{\mathrm{f}}$ is the greatest at $N_{\mathrm{f}}=1$ and gets smaller as $N_{\mathrm{f}}$ increases, finally converging at around $N_{\mathrm{f}}=5$. Note that both $E_{\mathrm{sec}}$ and $q_{\mathrm{f}}$ for the Touhoro volcanic soil, which has a higher particle crushability, are lower than those for the Tomikawa volcanic soil. Figure 16 shows the relationship between the deviator stress at failure $\left(q_{\mathrm{f}}\right)$ and the effective mean principal stress at failure $\left(p_{\mathrm{f}}^{\prime}\right)$ in freeze-thaw $\mathrm{CD}$ and $\overline{\mathrm{CU}}$ tests for the two volcanic soils under different confining pressures. Figure 16 also shows the effective stress paths derived from the $\overline{\mathrm{CU}}$ tests. For plots with the same $p_{\mathrm{f}}^{\prime}$, the effective stress ratio at failure $\left(\eta_{\mathrm{f}}=q_{\mathrm{f}} / p_{\mathrm{f}}^{\prime}\right)$ decreases with an increasing $N_{\mathrm{f}}$, while for plots with the same $N_{\mathrm{f}}, \eta_{\mathrm{f}}$ is thought to be almost constant as the $q_{\mathrm{f}}-p_{\mathrm{f}}^{\prime}$ relationships seem to be linear. Moreover, in the $\overline{\mathrm{CU}}$ tests on the Touhoro volcanic soil, shearing induces a continuous contraction, while the Tomikawa volcanic soil shows phase transformation behavior from contraction to dilation. In addition,

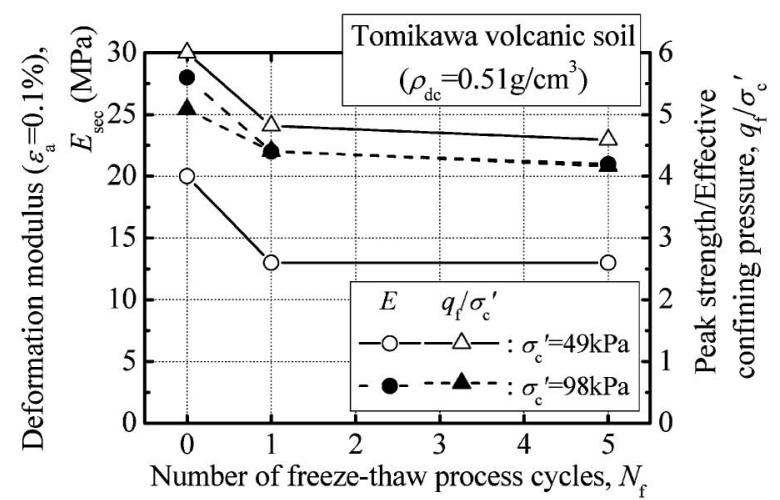

(a) Tomikawa volcanic soil

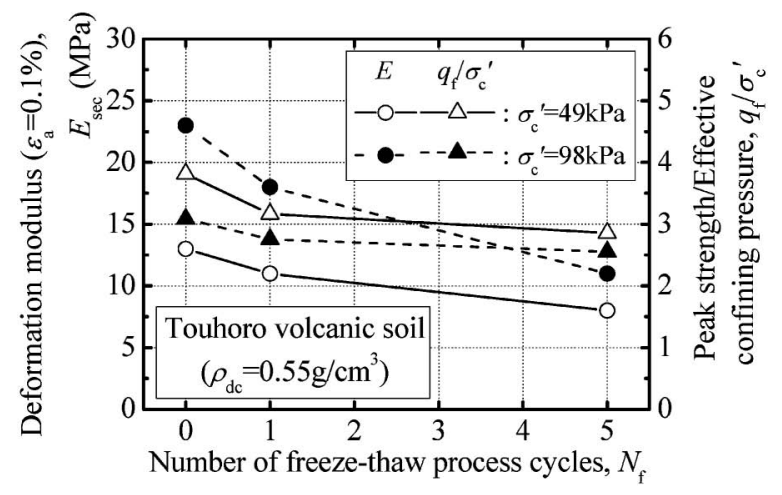

(b) Touhoro volcanic soil

Fig. 15. Influence of freeze-thaw history on deformation-strength characteristics for specimens with the same $\rho_{\mathrm{dc}}$

regardless of the effective stress paths, the freeze-thaw history of the specimens promotes a tendency toward contraction in the $\overline{\mathrm{CU}}$ tests for both volcanic soils. Note that the difference in the effect of the freeze-thaw action on the contraction behavior between the $\overline{\mathrm{CU}}$ tests (Fig. 16(b)) and the CD tests (Fig. 12(b)) is thought to be caused by the difference in drainage conditions and the effective mean principal stress, as reported by Miura et al. (1996a).

Miura et al. (1996a) revealed that the unique relationship between the internal friction angle $\left(\phi_{\mathrm{d}}\right.$ or $\left.\phi^{\prime}\right)$ and the effective mean principal stress at failure $\left(p_{\mathrm{f}}^{\prime}\right)$ is identified for each volcanic coarse-grained soil independent of the difference in effective stress paths in the CD and $\overline{C U}$ tests. Accordingly, this study assumes that the rupture envelop is uniquely defined at every freeze-thaw process cycle $\left(N_{\mathrm{f}}\right)$, regardless of the drainage conditions. Besides, it is reported that for crushable volcanic coarse-grained soils, the rupture envelop curves slightly under the influence of particle breakage, leading to the appearance of apparent cohesion (Yagi and Miura, 2004). However, since it is hard to image that disturbed fallen pumice stone, a coarse-grained and non-plastic geomaterial, has true cohesion, we adopt the secant internal friction angle calculated with Eq. (3), as recommended in JGS (2009).

$$
\phi_{\mathrm{d}}, \phi^{\prime}=\sin ^{-1}\left(\frac{\sigma_{1}^{\prime}-\sigma_{3}^{\prime}}{\sigma_{1}^{\prime}+\sigma_{3}^{\prime}}\right)_{\max }
$$

Here, $\sigma_{1}^{\prime}$ and $\sigma_{3}^{\prime}$ are the maximum and the minimum effec- 


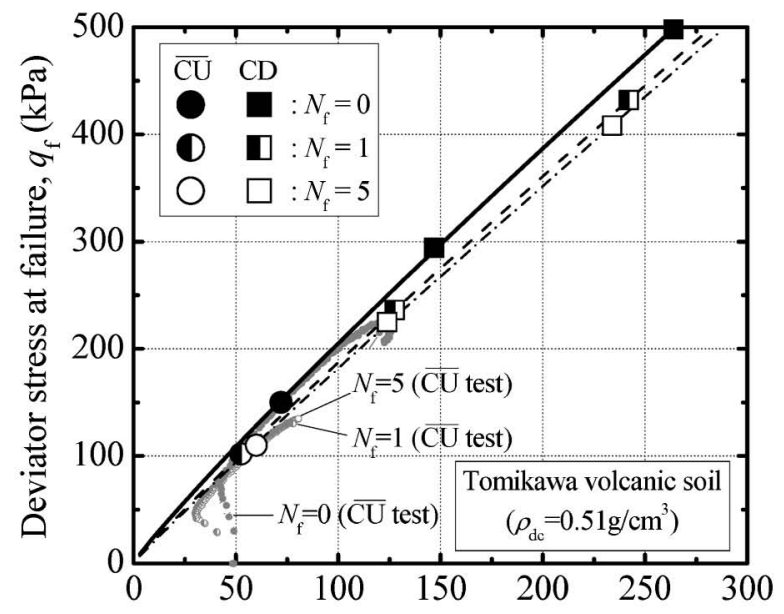

Effective mean principal stress at failure, $p_{\mathrm{f}}{ }^{\prime}(\mathrm{kPa})$

(a) Tomikawa volcanic soil

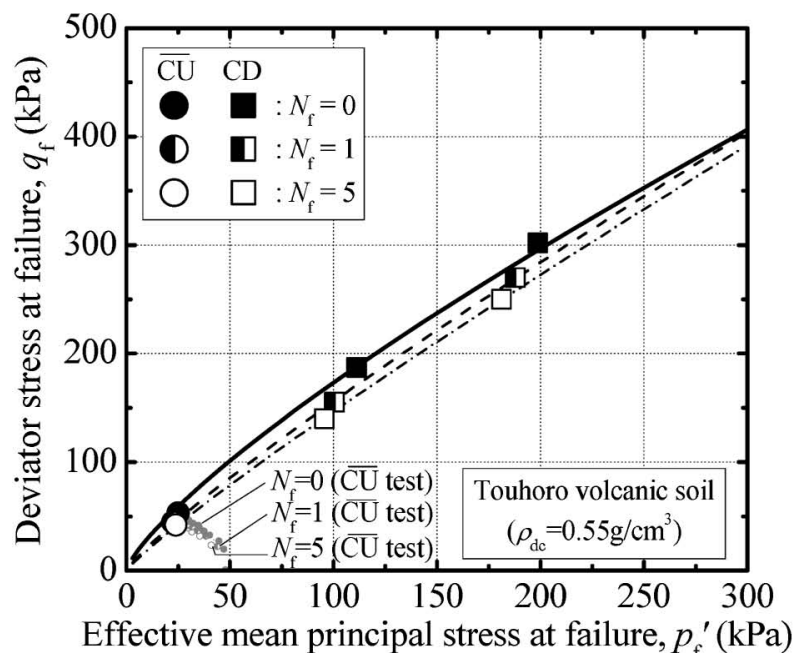

(b) Touhoro volcanic soil

Fig. 16. Influence of freeze-thaw history on effective stress ratio

tive principal stresses, respectively. $\phi_{\mathrm{d}}$ and $\phi^{\prime}$ are the internal friction angles derived from the $\mathrm{CD}$ and the $\overline{\mathrm{CU}}$ tests, respectively.

The internal friction angle $\left(\phi_{\mathrm{d}}\right.$ or $\left.\phi^{\prime}\right)$, derived from Fig. 16 , is plotted against the effective mean principal stress at failure $\left(p_{\mathrm{f}}^{\prime}\right)$ and the effective confining pressure $\left(\sigma_{\mathrm{c}}^{\prime}\right)$ in Fig. 17 . For plots with the same $p_{\mathrm{f}}^{\prime}$ or $\sigma_{\mathrm{c}}^{\prime}$, the internal friction angle decreases with an increasing $N_{\mathrm{f}}$, while for plots with the same $N_{\mathrm{f}}$, it decreases with an increasing $p_{\mathrm{f}}^{\prime}$ or $\sigma_{\mathrm{c}}^{\prime}$. This indicates that the internal friction angle of crushable volcanic coarse-grained soils strongly depends on the stress levels, such as the effective confining pressure, and that the freeze-thaw action has a profound influence on the decrease in the shear strength of the crushable volcanic coarse-grained soil, especially under low effective confining pressure. Accordingly, it can be supposed that the influence of the freeze-thaw history on the mechanical behavior of crushable volcanic coarse-grained soils comes to the surface, especially at relatively low overburden

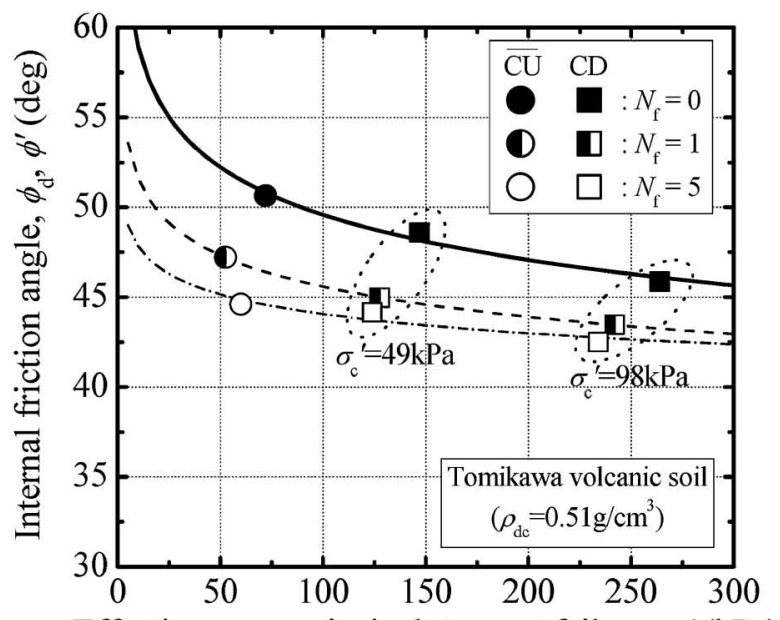

Effective mean principal stress at failure, $p_{\mathrm{f}}{ }^{\prime}(\mathrm{kPa})$

(a) $\phi_{\mathrm{d}}$ or $\phi^{\prime}-p_{\mathrm{f}}^{\prime}$ relationships for Tomikawa volcanic soil

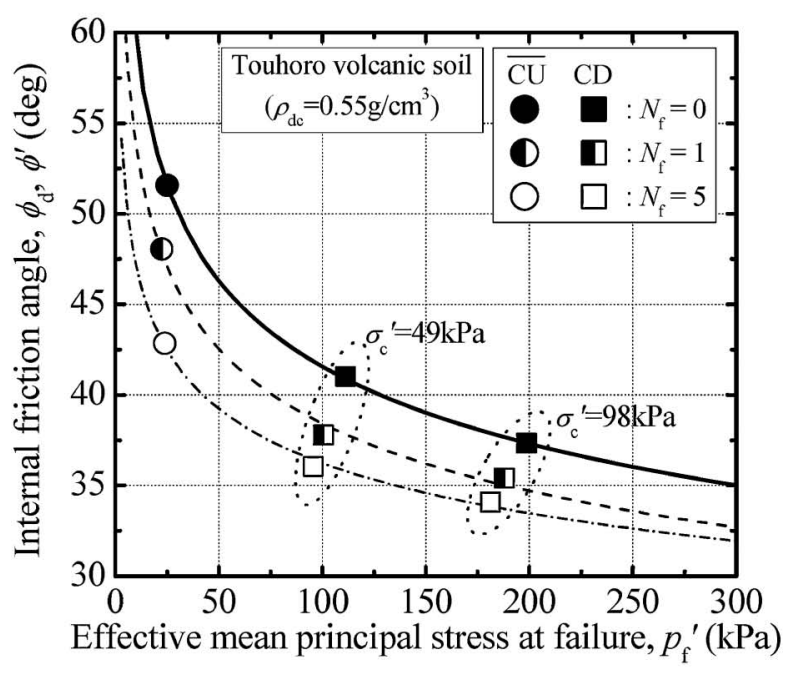

(b) $\phi_{\mathrm{d}}$ or $\phi^{\prime}-p_{\mathrm{f}}^{\prime}$ relationships for Touhoro volcanic soil

Fig. 17. Influence of freeze-thaw history on internal friction angle

pressure zones, such as subsurface layers subject to freeze-thaw action. Furthermore, Touhoro volcanic soil, with its higher particle crushability, showed a slightly greater drop in the internal friction angle than the Tomikawa volcanic soil. The effect of the freeze-thaw sequences on the relationships between the deformationstrength characteristics and the particle crushability will therefore be investigated in the next section.

\section{Particle Breakage due to Freeze-thaw Action}

We now discuss the effect of the freeze-thaw history on the particle crushability of volcanic coarse-grained soils, examined via triaxial compression tests. Figure 18 shows the grain-size distribution curves for the two volcanic soils before and after the freeze-thaw triaxial compression tests. As the freeze-thaw action is repeated, the mean grain size $\left(D_{50}\right)$ of both volcanic soils decreases because the particle breakage progresses. The effect of the freezethaw action is marked at $N_{\mathrm{f}}=1$, and it tends to converge 


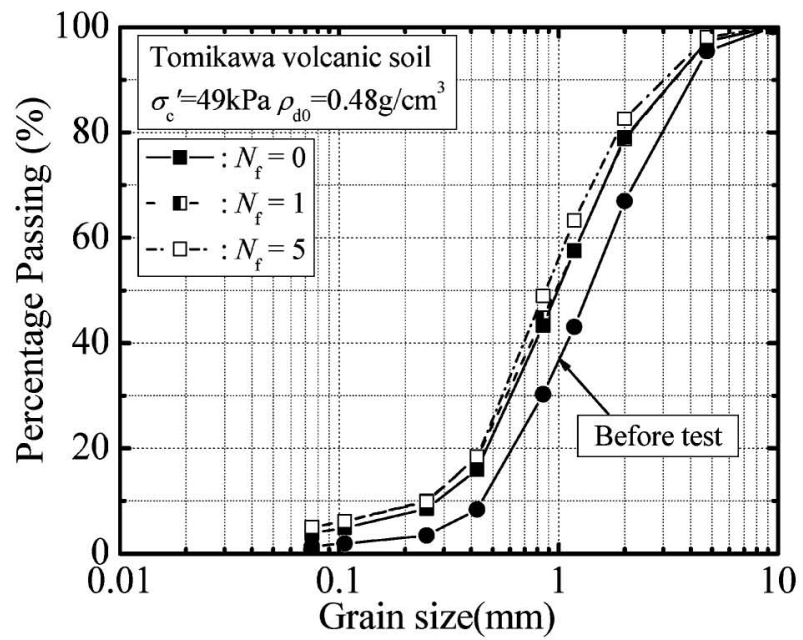

(a) Tomikawa volcanic soil

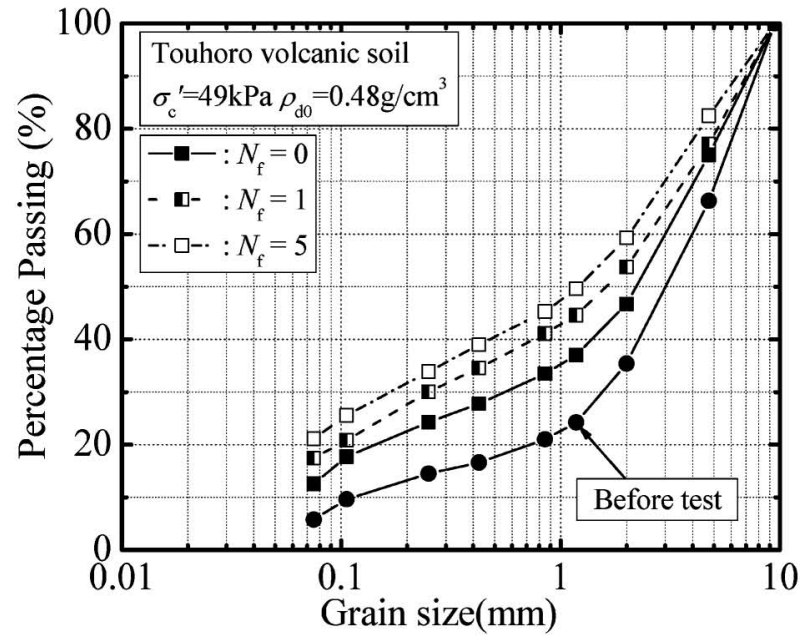

(b) Touhoro volcanic soil

Fig. 18. Influence of freeze-thaw history on grain-size distribution

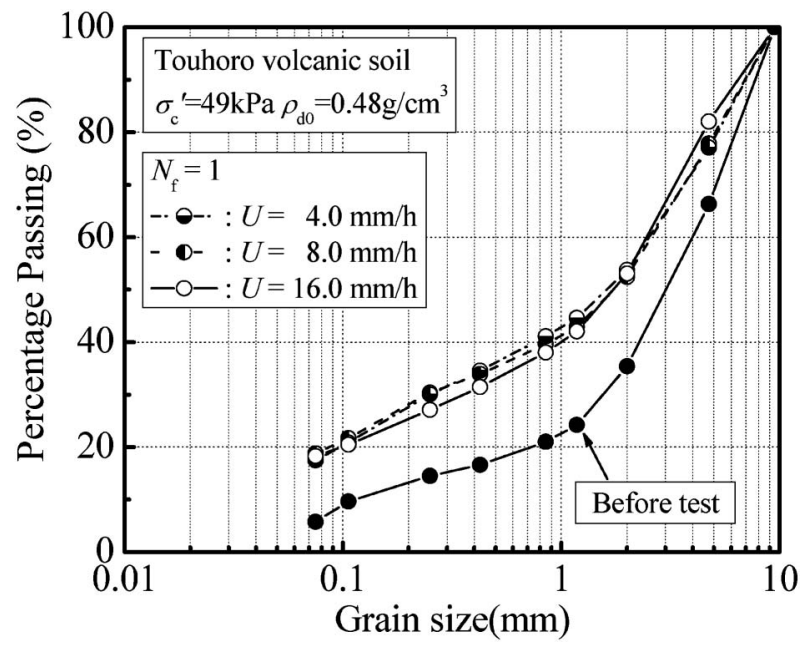

Fig. 19. Influence of freezing and thawing rate on grain-size distribution

as $N_{\mathrm{f}}$ increases. Moreover, according to Fig. 19, obtained from freeze-thaw triaxial compression tests under different freezing and thawing rates of the specimen, the freez-

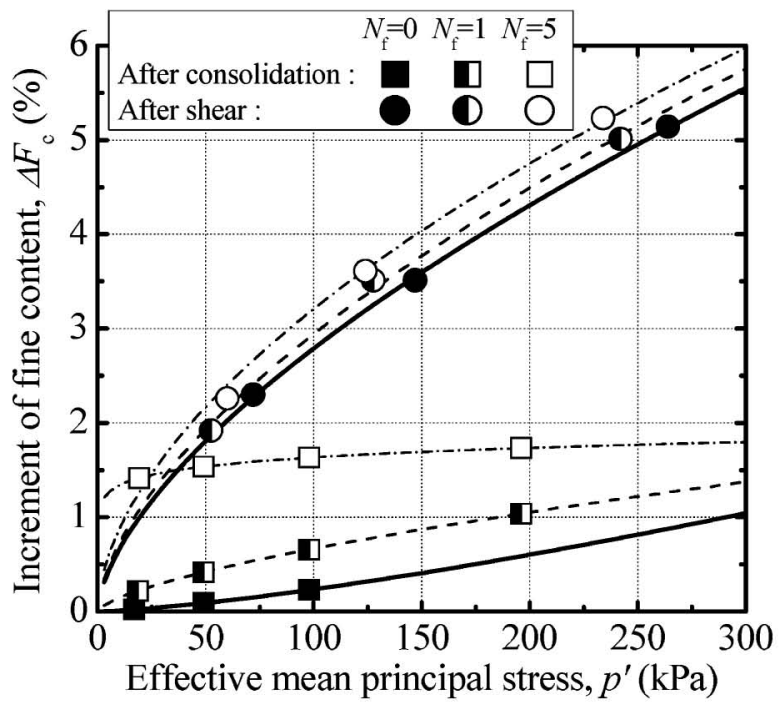

(a) Tomikawa volcanic soil

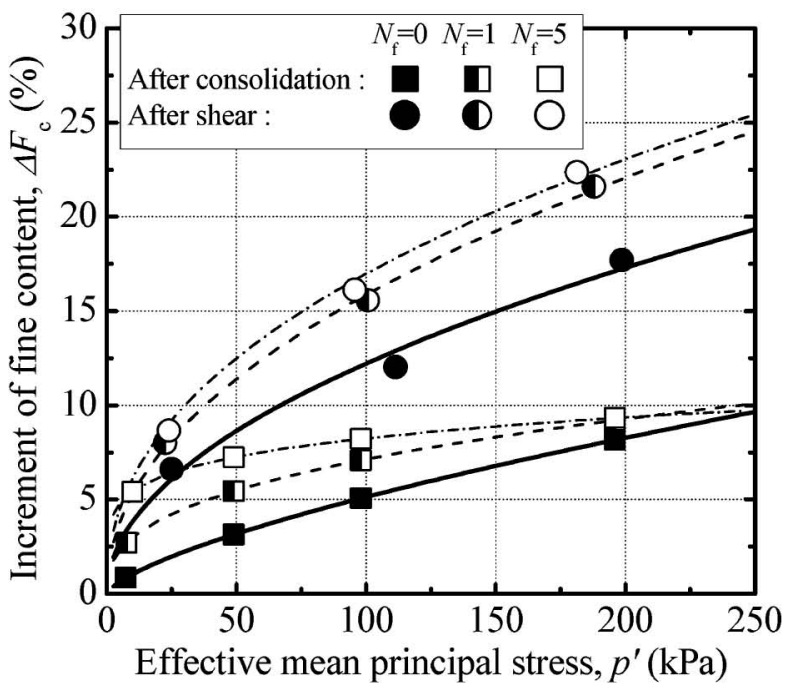

(b) Touhoro volcanic soil

Fig. 20. Influence of freeze-thaw history on particle crushability

ing and thawing rates have little influence on this behavior. Figure 20 shows the relationship between the increment in fines content $\left(\Delta F_{\mathrm{c}}\right)$ and the effective mean principal stress $\left(p^{\prime}\right)$, which were obtained separately from freeze-thaw triaxial compression tests either after isotropic consolidation or after shear under various $\sigma_{\mathrm{c}}^{\prime}$. Compared with the results for non-freeze-thawed specimens, $\Delta F_{\mathrm{c}}$ increases significantly with the freeze-thaw sequence; this tendency is even more remarkable with an increasing $N_{\mathrm{f}}$. The effect of $\Delta F_{\mathrm{c}}$, during isotropic consolidation, is marked at low effective mean principal stress $\left(p^{\prime}\right)$ in both volcanic soils, tending to converge with an increasing $p^{\prime}$. These figures indicate that the freeze-thaw history facilitates particle breakage during isotropic consolidation and shear in volcanic coarse-grained soils. The increase in particle breakage during isotropic consolidation is hence considered to have caused the decrease in the deformation modulus at the small levels of strain shown in Fig. 15. 
The effects of particle breakage due to freeze-thaw on the strength characteristics of both volcanic soil samples will now be discussed. Comparing Figs. 17 and 20, it is observed that the internal friction angle $\left(\phi_{\mathrm{d}}, \phi^{\prime}\right)$ of both volcanic soils decreases inversely with an increase in $\Delta F_{\mathrm{c}}$, regardless of the effective mean principal stress $\left(p^{\prime}\right)$. In addition, the relationships between the internal friction angle $\left(\phi_{\mathrm{d}}, \phi^{\prime}\right)$ and the increment in fines content $\left(\Delta F_{\mathrm{c}}\right)$ for both volcanic soils, obtained from the freeze-thaw triaxial compression tests, were examined (Fig. 21). The above-mentioned tendency for the strength to drop with an increase in $\Delta F_{\mathrm{c}}$ can be clearly seen, although the $\phi_{\mathrm{d}}$, $\phi^{\prime}-\Delta F_{\mathrm{c}}$ relationship differs according to the number of freeze-thaw process cycles $\left(N_{\mathrm{f}}\right)$. Furthermore, the Touhoro volcanic soil, with its higher particle crushability, showed a slightly greater drop in strength than the Tomikawa soil. Miura and Yamanouchi (1971) pointed out that the reduced dilation caused by particle breakage

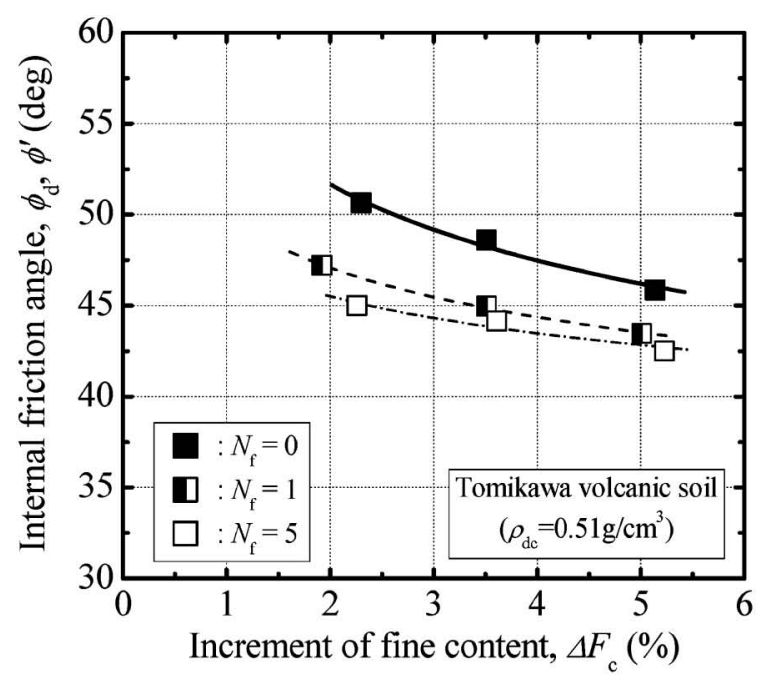

(a) Tomikawa volcanic soil

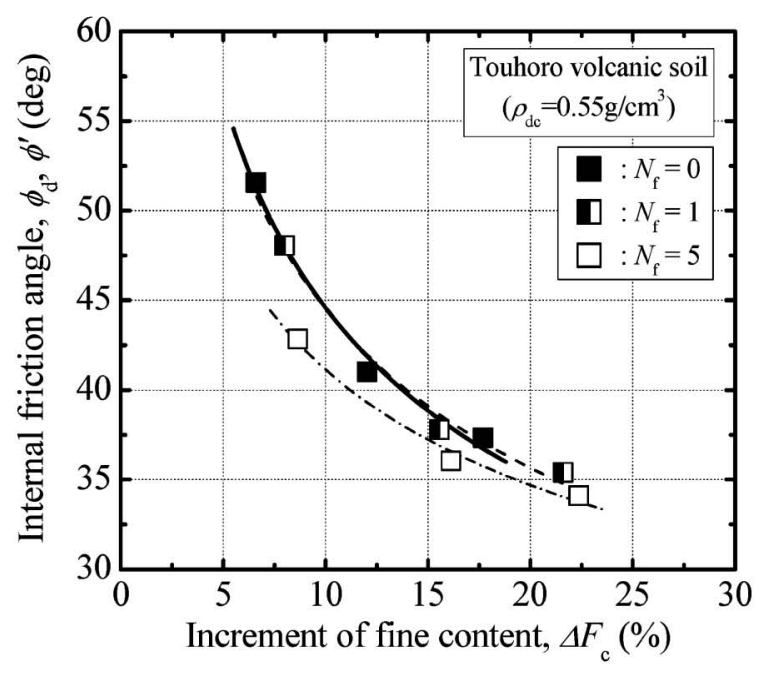

(b) Touhoro volcanic soil

Fig. 21. Comparison of $\phi^{\prime}-\Delta F_{\mathrm{c}}$ relationships under different freezethaw histories with increasing stress contributes to a drop in the internal friction angle. The reduction mechanism for the shear strength with freeze-thaw sequences seems to be similar to the mechanism of stress dependency arising from particle breakage in non-freeze-thawed specimens. However, since the $\phi_{\mathrm{d}}$ and $\phi^{\prime}-\Delta F_{\mathrm{c}}$ relationships cannot be uniquely defined, the effect of the freeze-thaw action cannot be represented only by $\Delta F_{\mathrm{c}}$.

From these results, it seems reasonable to conclude that the degradation in the deformation-strength characteristics (such as the internal friction angle and the deformation modulus) and the change in the dilatency characteristics of the crushable volcanic coarse-grained soils, caused by the freeze-thaw action, are mainly because of particle breakage during the consolidation and shear processes. However, there is room for further investigation as to the mechanism whereby the degree of particle breakage increases due to the freeze-thaw action.

\section{Effect of Freeze-thaw Method on Mechanical Behavior of Volcanic Coarse-grained Soils}

Now, we discuss the effect of the water content in the freeze-thaw process on the mechanical behavior of crushable volcanic coarse-grained soils. After setting an airdried specimen inside the triaxial cell, an unsaturated specimen in the freeze-thaw tests was prepared by permeating it with de-aired water for around 3 hours, followed by draining under gravity for 24 hours. The degree of saturation was approximately $60 \%$. The typical results of freeze-thaw tests for an unsaturated specimen of Tomikawa volcanic soil are shown in Fig. 22. The abovementioned in situ freezing and thawing settlement can be observed, although the amount of thawing settlement is slightly smaller compared to that shown in Fig. 8(b) because of the reduced hydraulic filling effect. Figure 23 compares $q-\varepsilon_{\mathrm{a}}-\varepsilon_{\mathrm{v}}$ relationships obtained from CD tests on the specimens undergoing freeze-thaw tests under saturated and unsaturated conditions. Note that all the triaxial compression tests were performed under saturated conditions. Figures 24 and 25 compare the $E_{\mathrm{sec}}-N_{\mathrm{f}}$ relationships and the $\phi_{\mathrm{d}}-p_{\mathrm{f}}^{\prime}$ relationships derived from Fig. 23 with the relationships in Figs. 15(a) and 17(a), respectively. The tendency for the strength and stiffness to decrease with freeze-thaw sequences can be clearly observed, as seen in the results of tests performed under saturated conditions, with the rate of decrease being approximately the same. Moreover, the dilatancy character-

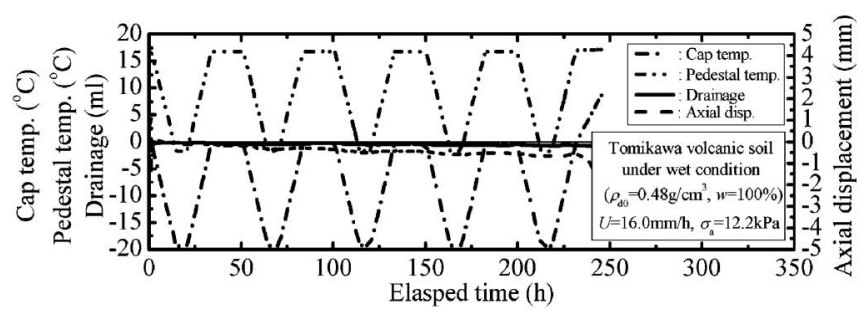

Fig. 22. Influence of water content in freeze-thaw process on frostheave behavior 


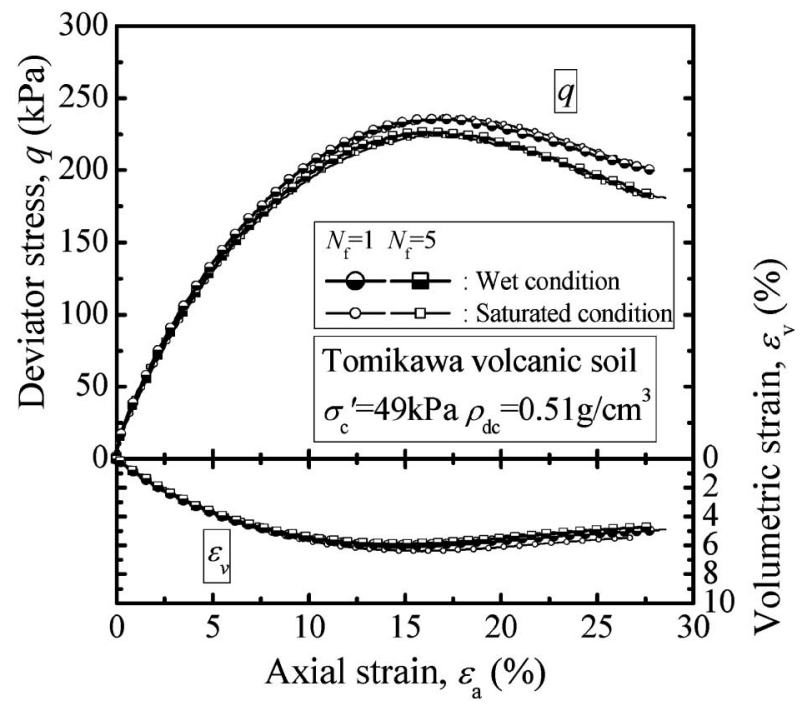

Fig. 23. Influence of water content in freeze-thaw process on stressstrain-dilatancy relationship

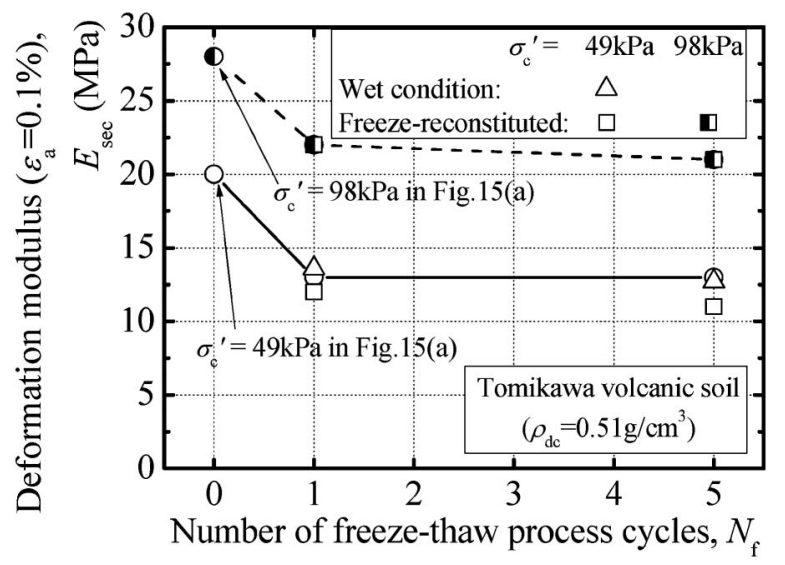

Fig. 24. Influence of freeze-thaw method on deformation modulus

istics equivalent to the results of tests performed under saturated conditions were also obtained, as shown in Fig. 23. Figure 26 shows the values of $\Delta F_{\mathrm{c}}$ generated through freeze-thaw triaxial compression tests plotted against $p_{\mathrm{f}}^{\prime}$, as well as the results of a regression analysis using Eq. (4) proposed by Miura et al. (1999) and shown in Fig. 20(a).

$$
\Delta F_{\mathrm{c}}=a\left(\frac{p_{\mathrm{f}}^{\prime}}{p_{0}^{\prime}}\right)^{\mathrm{b}} e^{\mathrm{c} \eta_{\mathrm{f}}}
$$

Here $a, b$, and $c$ are the regression constants corresponding to the material properties and the number of freeze-thaw process cycles, and $p_{0}^{\prime}$ is a unit pressure. Note that we assume the effective stress ratio at failure $\left(\eta_{\mathrm{f}}\right)$ to be constant at every $N_{\mathrm{f}}$. The $\Delta F_{\mathrm{c}}-p_{\mathrm{f}}^{\prime}$ relationships derived from the $\mathrm{CD}$ tests on specimens undergoing freeze-thaw tests under unsaturated conditions agree well with the regression analysis results appearing in Fig. 20(a). Accordingly, it seems reasonable to conclude that when a triaxial specimen still holds pore water after gravity dewatering, the water content during the freeze-thaw has little influence on the mechanical behavior of a crushable

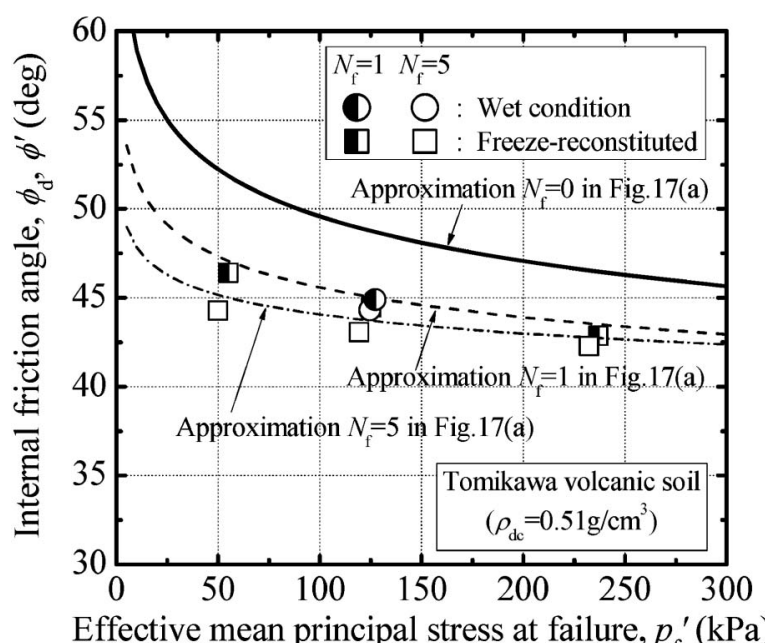

Fig. 25. Influence of freeze-thaw method on internal friction angle

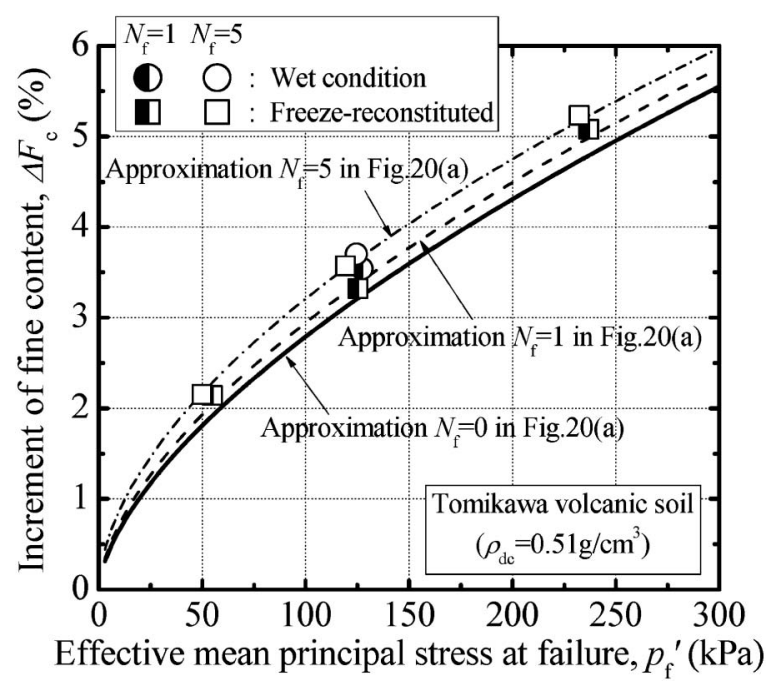

Fig. 26. Influence of freeze-thaw method on effective stress ratio

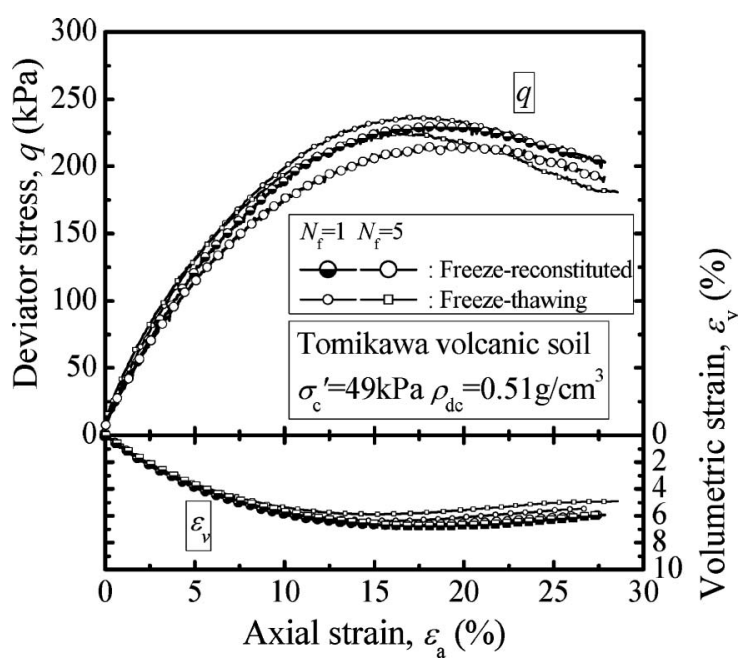

Fig. 27. Comparison of stress-strain-dilatancy relationships under different specimen preparations 
volcanic coarse-grained soil.

Next, we discuss the applicability of triaxial compression tests for freeze-reconstituted specimens to evaluate the effect of the freeze-thaw action on the mechanical behavior of volcanic coarse-grained soils as an alternative to freeze-thaw triaxial compression tests. Figure 27 compares $q-\varepsilon_{\mathrm{a}}-\varepsilon_{\mathrm{v}}$ relationships obtained from the CD tests on a freeze-reconstituted specimen, which has the same dry density after consolidation $\left(\rho_{\mathrm{dc}}\right)$ as that of the specimen undergoing the freeze-thaw tests under saturated conditions, to the results in Fig. 12(b). Furthermore, the results of the $\mathrm{CD}$ tests on the freeze-reconstituted specimen were plotted in Figs. 24-26. In all the figures, the quantitative difference between the two test results under the same experimental conditions (except for the preparation of the test specimens) can barely be observed for either the deformation-strength characteristics or the particle crushability. Accordingly, considering only the influence of the increased specimen density due to the freeze-thaw action, the difference in the freeze-thaw method for the volcanic soil samples has little influence on the mechanical behavior.

These results indicate that the pore water existing in the inter-particle voids may not influence the degradation of the mechanical properties or the particle crushability, although it induces the densification of the soil structure. However, pore water inside intra-particle voids may affect the mechanical properties and the particle crushability. Therefore, it seems reasonable to conclude that even if a saturated specimen has been freeze-thawed, the effects of the freeze-thaw action on the mechanical behavior of non-frost-susceptible volcanic coarse-grained soils can be evaluated simply by using freeze-reconstituted specimens made with freeze-thawed samples under the previously outlined saturated surface-dry conditions.

\section{Effect of Freeze-thaw Sequences on Single-particle Strength}

The effects of the freeze-thaw history on the particle crushability of volcanic coarse-grained soils are discussed in this section. Figure 28 shows the relationships between the strength of single-particle crushing $\left(S_{\mathrm{t}}\right)$ and the particle height at failure $\left(D_{\mathrm{f}}\right)$ obtained from single-particle crushing tests on Tomikawa volcanic soil exposed to different freeze-thaw histories, along with the results of the regression analysis using Eq. (5) (Miura et al., 1999).

$$
S_{\mathrm{t}}=m \cdot D_{\mathrm{f}}^{\mathrm{n}}
$$

Here, $m$ and $n$ are regression constants corresponding to the material properties and the number of freeze-thaw process cycles. The curves for Tomikawa and Touhoro volcanic soils from Eq. (5) are summarized in Fig. 29. From these curves, it can be observed that as the number of freeze-thaw process cycles $\left(N_{\mathrm{f}}\right)$ increases, the strength of the single-particle crushing $\left(S_{\mathrm{t}}\right)$ in both volcanic soils decreases, and the distribution of $S_{\mathrm{t}}$ widens. Furthermore, the Touhoro volcanic soil, with its higher particle crushability, displays single-particle hardness lower than that of the Tomikawa volcanic soil. These results indicate that the freeze-thaw action weakens the single-particle hardness of volcanic coarse-grained soils, although the degree of weakening varies from one particle to another, and the embrittlement of the soil particles increases the proportion of particles broken during loading due to the freeze-thaw. Therefore, it can be supposed that one of the

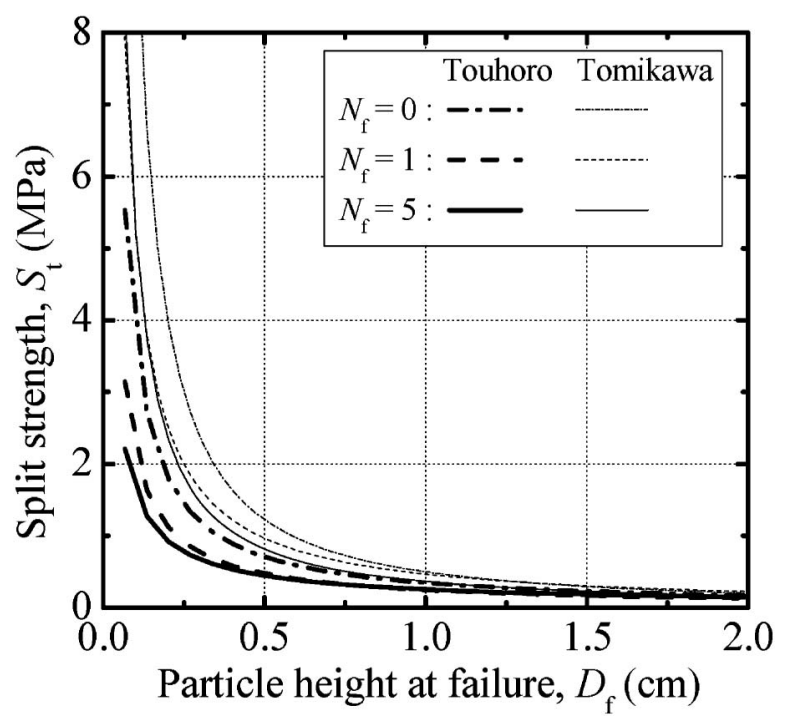

Fig. 29. Comparison of strength of single-particle crushing under different freeze-thaw histories
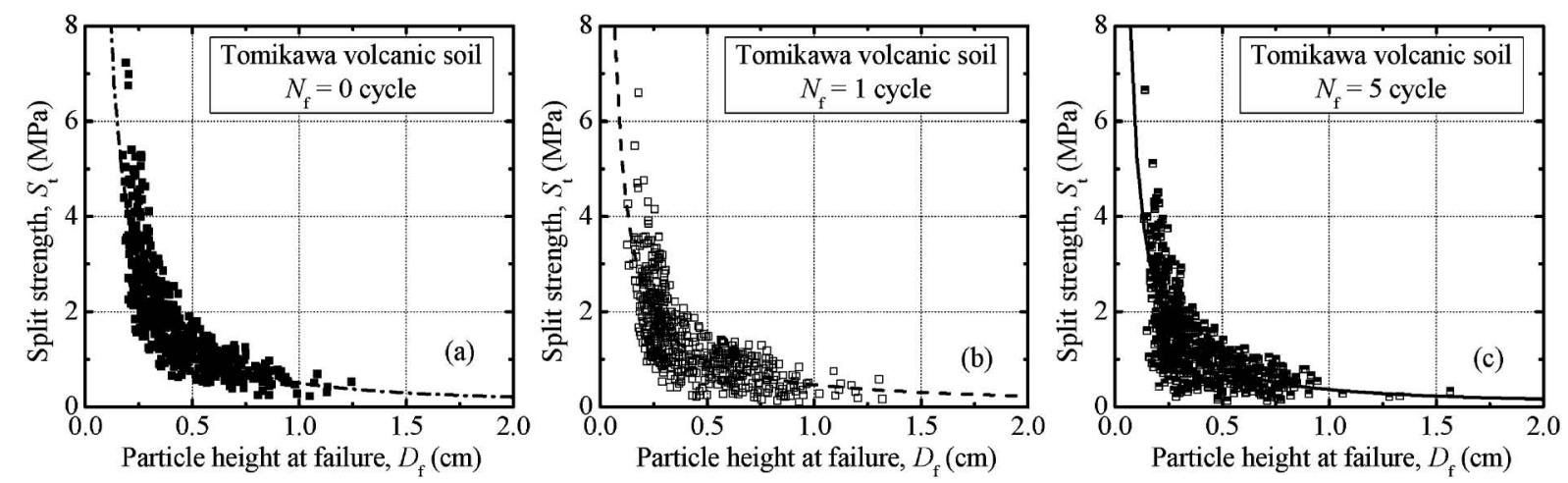

Fig. 28. Influence of freeze-thaw history on strength of single-particle crushing 
reasons why the freeze-thaw action reduces the shear strength of crushable volcanic coarse-grained soils is that the soil particles become fragile through the freeze-thaw action, causing an increased overall particle breakage during the freeze-thaw triaxial compression tests, and thus, a further reduction in strength. However, particle breakage under the point-loaded compression tests showed only one of many particle breakage patterns possible under consolidation or shear, so it only gives a rough estimate of the drop in the shear strength of the soil.

\section{CONCLUSIONS}

The following findings were obtained from the present study:

(1) Toyoura sand showed neither frost heave nor thaw settlement, and no particle breakage. The volcanic coarse-grained soils also exhibited no frost-heave behavior, but the freeze-thaw induced particle breakage led to the contraction and the densification of the soil specimens after further thawing with an increased number of freeze-thaw process cycles. Volcanic coarse-grained soil is a type of non-frost-susceptible geomaterial in which the in situ freezing of pore water is induced by a decrease in temperature.

(2) When the dry density of volcanic coarse-grained soils was fixed, the freeze-thaw action resulted in a decrease in the internal friction angle and deformation modulus, decreasing further with an increasing number of freeze-thaw process cycles. The effects of the freeze-thaw action were marked under low stress, being most evident at the start of the freeze-thaw sequences; and hence, it can be concluded that the freeze-thaw action has a noted influence on the degradation of the deformation-strength characteristics of volcanic coarse-grained soils, especially at the subsurface layer of fragmental soil grounds.

(3) Some cracks in very porous constituent particles may be expanded by the freezing pore water inside the intra-particle voids; and consequently, the freeze-thaw action can weaken the single-particle hardness of volcanic coarse-grained soils. The embrittlement of soil particles, due to the freeze-thaw action, increases the number of broken particles, leading to an overall increase in particle breakage, changes in the grain size distribution, and an increased fines content. The freeze-thaw history leads to increased particle breakage under isotropic consolidation and shear, increasing with the number of freeze-thaw process cycles and causing a resulting drop in strength and stiffness.

(4) As opposed to volcanic coarse-grained soils, no observable change in the stress-strain-dilatancy relationship before or after freeze-thaw could be discerned for the non-crushable sand. Accordingly, the degradation in the deformation-strength characteristics and the change in the dilatancy characteristics of the crushable volcanic coarse-grained soils, from the freeze-thaw action, can be assumed to originate mainly from the above-mentioned increase in particle breakage during isotropic consolidation and shear. In this case, the mechanism for the reduction in the shear strength in freeze-thawed volcanic coarsegrained soils is expected to be similar to that in crushable geomaterials exhibiting stress dependency arising from particle breakage.

(5) The pore water in inter-particle voids may not influence the degradation in the mechanical properties and the particle crushability, but pore water inside intra-particle voids may affect them. Therefore, the effects of the freeze-thaw action on the mechanical behavior of non-frost susceptible volcanic coarsegrained soils can be evaluated simply by using freezereconstituted specimens made with freeze-thawed samples under unsaturated conditions.

This study clarifies that even for a fragmental volcanic coarse-grained soil ground, where frost heave does not occur, an evaluation of the effect of the freeze-thaw history on the mechanical behavior, from the viewpoint of particle breakage, is essential for establishing a precise method for predicting natural disasters in cold regions. For example, when volcanic coarse-grained soils are utilized as banking materials for the construction of new roads or railroads, or when a natural volcanic coarsegrained soil ground is excavated, sufficient attention should be given to the influence of the freeze-thaw action on the stability of the embankment and/or the cut slope for several years after the construction in terms of design and maintenance. This is because cyclic freeze-thaw action might gradually degrade the deformation-strength characteristics, although the degradation converges with time. However, there is room for further investigation to understand the mechanism by which particle breakage increases through the freeze-thaw action, the influence of the cyclic freeze-thaw action on the degradation of the deformation-strength characteristics in comparison with the role of wet-dry cycles, and the applicability of the conclusions in this study to other volcanic soils with differing formation histories and depositional environments (including geology, topography, and climate conditions).

\section{ACKNOWLEDGMENTS}

The authors would like to thank Mr. Yuta Ozaki, formerly of Hokkaido University, who performed the laboratory shear tests and arranged the experimental results. This research was supported in part by the Committee on Advanced Road Technology of the Ministry of Land, Infrastructure, Transport and Tourism, Japan and a Grant-in-Aid for Scientific Research (A) from the Japan Society for the Promotion of Science (JSPS).

\section{REFERENCES}

1) Ampadu, S. K. and Tatsuoka, F. (1993): Effect of setting method on the behaviour of clays in triaxial compression from saturation to undrained shear, Soils and Foundations, 33(2), 14-34. 
2) Aoyama, K., Ogawa, S., Kawasumi, O., Tamura, T. and Fukuda, M. (1977): Properties of soils subjected to freeze-thaw action, Soil Mechanics and Foundation Engineering, 25(7), 41-46 (in Japanese).

3) Aoyama, K., Ogawa, S. and Fukuda, M. (1979): Mechanical properties of soils subjected to freeze-thaw action, Proc. of the 34th Annual Conference of the Japan Society of Civil Engineers, 3, 719-720 (in Japanese).

4) Goto, S. and Tatsuoka, F. (1988): Influence of several testing conditions in triaxial compression tests on sands and gravels, Soil Mechanics and Foundation Engineering, 36(9), 13-18 (in Japanese).

5) Goto, S. (1993): Influence of a freeze and thaw cycle on liquefaction resistance of sandy soils, Soils and Foundations, 33(4), 148-158.

6) Hiramatsu, Y., Oka, Y. and Kiyama, H. (1965): Rapid tensile strength tests of rock with non-shaping test pieces, Bulletin of Japan Mining Industry Association, 81, 1024-1030 (in Japanese).

7) Ishikawa, T., Ozaki, Y. and Miura, S. (2008): Influence of freezethaw action on mechanical behavior of crushable volcanic coarsegrained soils, Journal of Geotechnical Engineering, C64(3), $712-717$ (in Japanese)

8) Japanese Geotechnical Society (2000): Preparation of soil specimens for triaxial tests (JGS 0520-2000), Standards of Japanese Geotechnical Society for Laboratory Shear Test, 1-7.

9) Japanese Geotechnical Society (2003): Test method for frost susceptibility of soils (JGS 0172-2003), Standards of Japanese Geotechnical Society for Laboratory Soil Testing Methods, 45-50.

10) Japanese Geotechnical Society (2009): Japanese Standards and Explanations of Laboratory Tests of Geomaterials, 1002 (in Japanese).

11) Miura, N., and Yamanouchi, T. (1971): Drained shear characteristics of standard sand under high confining pressures, Journal of Geotechnical Engineering, 193, 69-79 (in Japanese).

12) Miura, S. and Toki, S. (1982): A sample preparation method and its effect on static and cyclic deformation-strength properties of sand, Soils and Foundations, 22(1), 61-77.
13) Miura, S., Yagi, K. and Kawamura, S. (1996a): Static and cyclic shear behavior and particle crushing of volcanic coarse grained soils in Hokkaido, Journal of Geotechnical Engineering, 547/III-36, 159-170 (in Japanese).

14) Miura, S., Yagi, K. and Kawamura, S. (1996b): Effect of stress history on cyclic undrained deformation-strength characteristics of volcanic coarse grained soils, Journal of Geotechnical Engineering, 547/III-36, 221-229 (in Japanese).

15) Miura, S. and Yagi, K. (1997): Particle breakage of volcanic coarsegrained soils and its evaluation, Journal of Geotechnical Engineering, 561/III-38, 257-269 (in Japanese).

16) Miura, S., Kayaba, N. and Yagi, K. (1999): Some factors affecting the particle split strength of volcanic coarse-grained soils, Proc. of the 34th Japan National Conference on Geotechnical Engineering, 719-720 (in Japanese).

17) Miura, S. and Yagi, K. (2003): Mechanical behaviour and particle crushing of volcanic coarse-grained soils in Japan, Characterisation and Engineering Properties of Natural Soils, Proc. Intern. Workshop (eds. by Tan et al.), Singapore, 2-4 December 2002: 1169-1203.

18) Nakata, T., Miura, S. and Kawamura, S. (1998): Particle breakage and its evaluation of volcanic coarse-grained soils, Problematic Soils IS-TOHOKU'98, Proc. Intern. Symp. (eds. by Yanagisawa et al.), Sendai, 28-30 October 1998: 145-148.

19) Nakata, T. and Miura, S. (2007): Change in void structure due to particle breakage of volcanic coarse grained soil and its evaluation, Journal of Geotechnical Engineering, 63(1), 224-236 (in Japanese).

20) Ono, T. and Wada, T. (2003): The properties of normally and overconsolidated clay after freezing and thawing history, Journal of Geotechnical Engineering, 743/III-64, 47-57 (in Japanese).

21) Qi, J., Vermeer, P. A. and Cheng, G. (2006): A review of the influence of freeze-thaw cycles on soil geotechnical properties, Permafrost and Periglacial Processes, 17, 245-252.

22) Yagi, K. and Miura, S. (2004): Evaluation of mechanical characteristics for crushable volcanic soil ground, Journal of Geotechnical Engineering, 757/III-66, 221-234 (in Japanese). 